\title{
The CanPain SCl clinical practice guidelines for rehabilitation management of neuropathic pain after spinal cord injury: 2021 update
}

\author{
Eldon Loh ${ }^{1,2,3,4 凶}$, Magdalena Mirkowski iD ${ }^{1,2}$, Alexandria Roa Agudelo ${ }^{1}$, David J. Allison ${ }^{1}$, Brooke Benton ${ }^{5}$, Thomas N. Bryce ${ }^{5}$, \\ Sara Guilcher (D) $^{6}$, Tara Jeji ${ }^{7}$, Anna Kras-Dupuis ${ }^{2}$, Denise Kreutzwiser ${ }^{4}{ }^{4}$, Oda Lanizi ${ }^{8}$, Gary Lee-Tai-Fuy ${ }^{2}$, James W. Middleton (iD ${ }^{9,10}$, \\ Dwight E. Moulin ${ }^{3,4}$, Colleen $\mathrm{O}^{\prime}$ Connell ${ }^{11,12}$, Steve Orenczuk ${ }^{2}$, Patrick Potter ${ }^{2,3}$, Christine Short ${ }^{12,13}$, Robert Teasell ${ }^{1,3}$, Andrea Townson ${ }^{14}$, \\ Eva Widerström-Noga ${ }^{15,16}$, Dalton L. Wolfe ${ }^{1,2}$, Nancy Xia ${ }^{8}$ and Swati Mehta ${ }^{1,3}$
}

(c) The Author(s) 2022

STUDY DESIGN: Clinical practice guidelines.

OBJECTIVES: The objective was to update the 2016 version of the Canadian clinical practice guidelines for the management of neuropathic pain in people with spinal cord injury (SCI).

SETTING: The guidelines are relevant for inpatient, outpatient and community SCl rehabilitation settings in Canada.

METHODS: The guidelines were updated in accordance with the Appraisal of Guidelines for Research and Evaluation II tool. A Steering Committee and Working Group reviewed the relevant evidence on neuropathic pain management (encompassing screening and diagnosis, treatment and models of care) after $\mathrm{SCl}$. The quality of evidence was scored using Grading of Recommendations Assessment, Development and Evaluation (GRADE). A consensus process was followed to achieve agreement on recommendations and clinical considerations.

RESULTS: The working group identified and reviewed 46 additional relevant articles published since the last version of the guidelines. The panel agreed on 3 new screening and diagnosis recommendations and 8 new treatment recommendations. Two key changes to these treatment recommendations included the introduction of general treatment principles and a new treatment recommendation classification system. No new recommendations to model of care were made.

CONCLUSIONS: The CanPainSCI recommendations for the management of neuropathic pain after $\mathrm{SCl}$ should be used to inform practice.

Spinal Cord (2022) 60:548-566; https://doi.org/10.1038/s41393-021-00744-z

\section{INTRODUCTION}

Neuropathic pain (NP) presents significant challenges to those living with spinal cord injury $(\mathrm{SCl})$, with negative effects on function participation, (e.g., mood, sleep), and quality of life. For clinicians, providing support for those with NP after $\mathrm{SCl}$ continues to be a challenge. The 2016 CanPainSCl Clinical Practice Guidelines (CPG) formalized a series of recommendations for the rehabilitation management of $\mathrm{NP}$ after $\mathrm{SCl}$ [1]. These guidelines were developed in accordance with the Appraisal of Guidelines for Research \& Evaluation (AGREE) II tool [2], and focused on three domains: screening and diagnosis [3], treatment (both pharmacologic and non-pharmacologic) [4], and models of care [5].

The current document presents updates to the CanPainSCl CPG based on additional relevant literature that has been published since the first iteration of the guidelines. The ongoing goals of these CPG are to (1) provide practical and actionable guidelines with a strong rating on the AGREE-II scale, (2) support standardized care in the rehabilitation management of NP after $\mathrm{SCl}$, and (3) identify opportunities for further research in this area.

As in the 2016 CPG, an international group of experts formed a Working Group (WG) that would update the CanPainSCl guidelines under the direction of the Steering Committee (SC).

\section{SCOPE AND PURPOSE}

The scope and purpose of these guidelines are unchanged from the 2016 version. The target population to which these CPG apply includes adults living with $\mathrm{SCl}$ who are in the subacute phase of

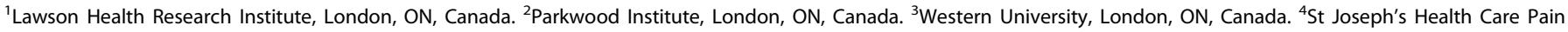

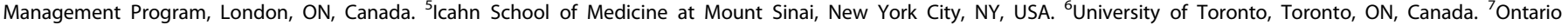

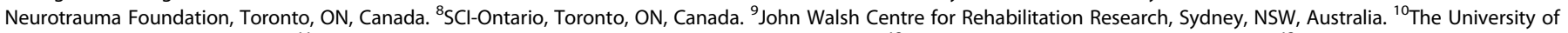

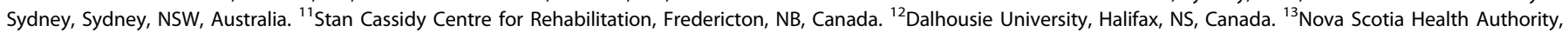

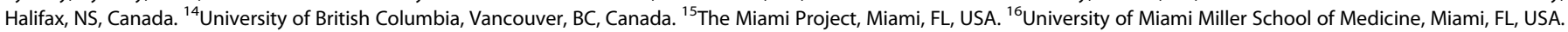

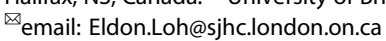


inpatient rehabilitation management to those living in the community. It excludes those being cared for in an acute care setting immediately after their initial injury. These guidelines are intended to be used by clinicians who care for those with $\mathrm{SCl}$. Researchers and health policy experts will also find these guidelines valuable.

\section{METHODS}

The overall CPG update process was overseen by the SC (EL, ARA, MM JWM, SM) with ongoing input and review from the WG. A facilitator (EJM) assisted with organizing and planning meetings. The CPG update methodology followed a similar process as the initial 2016 CPG, in accordance with the AGREE II tool. The main steps of this process involved: (1) identifying experts for the new 2020 WG, (2) updating literature search and review, (3) evaluating the quality of evidence using a modified Grading of Recommendations Assessment, Development and Evaluation (GRADE) approach, (4) discussing the updated evidence with WG members to develop and suggest modifications to existing recommendations or to propose new recommendations, and (5) voting on the recommendations and guidelines. The update was funded by the Ontario Neurotrauma
Foundation (ONF); guideline development was editorially independent from the funder.

\section{Working group composition}

Experts who were involved in the initial 2016 CanPainSCI CPG WG were invited to participate in the 2020 WG. New members were recruited if previous WG members were unable to participate or if their discipline/area of professional expertise was not represented in the 2016 WG composition. Representation from a broad spectrum of disciplines that reflected a national and international geographic distribution was sought. Experts from physiatry, pain medicine, psychology, pharmacy, occupational therapy, physical therapy, nursing, and research were included. Those with lived experience were also included in the WG, as were representatives from the ONF and a peer advocacy organization (SCl-Ontario) (Table 1). WG members were asked to provide a list of potential conflicts of interest prior to participating in meetings. If a member was felt to have a potential conflict with an item to be voted on or discussed, they could voluntarily withdraw from voting/discussing that item. If the chair assessed that a member may have a conflict of interest on a particular item, the chair would ask a particular member to withdraw/abstain from discussing that specific item. Prior to final submission of the manuscript, WG

Table 1. CanPainSCI Working Group.

\begin{tabular}{|c|c|}
\hline Member & Affiliation \\
\hline ARA $^{a}$ & Lawson Health Research Institute, London, ON, Canada \\
\hline $\mathrm{BB} \mathrm{RDH}, \mathrm{BSc}^{\mathrm{a}}$ & Icahn School of Medicine at Mount Sinai, New York City, NY, USA \\
\hline TNB MD & $\begin{array}{l}\text { Department of Rehabilitation and Human Performance, Icahn } \\
\text { School of Medicine at Mount Sinai, New York City, NY, USA }\end{array}$ \\
\hline SG, PT, PhD & University of Toronto, Toronto, ON, Canada \\
\hline TJ, MD & Ontario Neurotrauma Foundation, Toronto, On, Canada \\
\hline AK-D RN, MScN, CNNC,CRN & Parkwood Institute, London, ON, Canada \\
\hline DK, BScPhm, PharmD, ACPR & $\begin{array}{l}\text { St. Joseph's Health Care Pain Management Program, London, } \\
\text { ON, Canada }\end{array}$ \\
\hline $\mathrm{OL}$ & SCl-Ontario, Toronto, ON, Canada \\
\hline GL-T-F & Parkwood Institute, London, ON, Canada \\
\hline EL MD, $\operatorname{FRCP}(C)^{b}$ & $\begin{array}{l}\text { Lawson Health Research Institute, St. Joseph's Health Care Pain } \\
\text { Management Program, Western University, London, ON, Canada }\end{array}$ \\
\hline SM MA, PhD ${ }^{a}$ & $\begin{array}{l}\text { Lawson Health Research Institute, Western University, London, } \\
\text { ON, Canada }\end{array}$ \\
\hline $\begin{array}{l}\text { MM MSc, MScOT, OT Reg. } \\
\text { (Ont.) }\end{array}$ & $\begin{array}{l}\text { Parkwood Institute Research, Lawson Health Research Institute, } \\
\text { London, ON, Canada }\end{array}$ \\
\hline DEM MD, FRCP(C) & $\begin{array}{l}\text { St. Joseph's Health Care Pain Management Program, Western } \\
\text { University, London, ON, Canada }\end{array}$ \\
\hline $\mathrm{CO}^{\prime} \mathrm{C} M \mathrm{MD}, \mathrm{FRCP}(\mathrm{C})$ & $\begin{array}{l}\text { Stan Cassidy Centre for Rehabilitation and Dalhousie University } \\
\text { Faculty of Medicine, Fredericton, NB, Canada }\end{array}$ \\
\hline SO PsyD & Parkwood Institute, London, ON, Canada \\
\hline PP MD, FRCP(C) & Western University, Parkwood Institute, London, ON, Canada \\
\hline $\begin{array}{l}\text { JWM MBBS, PhD, FAFRM } \\
\text { (RACP) }\end{array}$ & $\begin{array}{l}\text { John Walsh Centre for Rehabilitation Research, The University of } \\
\text { Sydney, Sydney, NSW, Australia }\end{array}$ \\
\hline CS MD, FRCP(C), FACP & $\begin{array}{l}\text { Dalhousie University and Nova Scotia Health Authority, Halifax, } \\
\text { NS, Canada }\end{array}$ \\
\hline RT MD, FRCP(C) & $\begin{array}{l}\text { Lawson Health Research Institute, Western University, London, } \\
\text { ON, Canada }\end{array}$ \\
\hline AT MD, FRCPC, MSCHPEd & University of British Columbia, Vancouver, BC, Canada \\
\hline EW-N DDS, PhD & $\begin{array}{l}\text { The Miami Project, University of Miami, Miller School of Medicine, } \\
\text { Miami, FL, USA }\end{array}$ \\
\hline DLW PhD & $\begin{array}{l}\text { Parkwood Institute Research, Lawson Health Research Institute, } \\
\text { London, ON, Canada }\end{array}$ \\
\hline NX & SCl-Ontario, Toronto, ON, Canada \\
\hline$D J A^{a}$ & Lawson Health Research Institute, London, ON, Canada \\
\hline
\end{tabular}

\section{Member \\ ARA $^{\mathrm{a}}$}

$\mathrm{BB} \mathrm{RDH}, \mathrm{BSc}^{\mathrm{a}}$

SG, PT, PhD

TJ, MD

AK-D RN, MSCN, CNNC,CRN

$\mathrm{OL}$

GL-T-F

SM MA, PhDa

MM MSc, MScOT, OT Reg.

(Ont.)

DEM MD, FRCP(C)

\section{$\mathrm{CO}^{\prime} \mathrm{C} M \mathrm{MD}, \mathrm{FRCP}(\mathrm{C})$}

SO PsyD

PP MD, FRCP(C)

JWM MBBS, PhD, FAFRM

(RACP)

RT MD, FRCP(C)

AT MD, FRCPC, MSCHPEd

EW-N DDS, PhD

${ }^{\mathrm{b}}$ Chair.

\section{Professional role}

Research Assistant

Clinical Research Coordinator

Professor, Physiatrist

Physiotherapist, Assistant Professor

Program Director, Lived Experience

Clinical Nurse Specialist

Clinical pharmacist

Lived Experience

Occupational Therapist

Physiatrist, Associate Professor

Psychologist, Scientist

Research Fellow

Professor, Earl Russell Chair, Pain Research, Neurologist

Physiatrist, Research Chief, Assistant Professor

Psychologist

Physiatrist

Professor, Physiatrist

Department head/ Chief Medicine, Associate Professor, Physiatrist

Physiatrist, Scientist

Clinical Professor, Physiatrist

Research Professor

Scientist

Lived Experience

Research Associate 


\section{Table 2. Disclosures of the CanPainSCI CPG group.}

\begin{tabular}{|c|c|}
\hline Member & Disclosures \\
\hline ARA & ARA has nothing to disclose. \\
\hline DJA & DJA has nothing to disclose. \\
\hline BB & BB has nothing to disclose \\
\hline TNB & TNB has nothing to disclose. \\
\hline SG & SG has nothing to disclose. \\
\hline TJ & $\mathrm{TJ}$ is employed by the Ontario Neurotrauma Foundation. \\
\hline AK-D & AK-D has nothing to disclose. \\
\hline DK & DK has nothing to disclose. \\
\hline $\mathrm{OL}$ & OL has nothing to disclose. \\
\hline GL-T-F & GL-T-F has nothing to disclose. \\
\hline EL & EL has nothing to disclose. \\
\hline SM & SM has nothing to disclose. \\
\hline MM & MM has nothing to disclose. \\
\hline DEM & $\begin{array}{l}\text { DEM reports personal fees from Canopy Growth Inc, } \\
\text { outside the submitted work. }\end{array}$ \\
\hline $\mathrm{CO}^{\prime} \mathrm{C}$ & $\begin{array}{l}\text { CO'C reports grants from Praxis Spinal Cord Institute, } \\
\text { other from Cytokinetics, other from Orion, other from } \\
\text { Mallinckrodt, grants from New Brunswick Health Research } \\
\text { Foundation, personal fees from Spectrum/Canopy, } \\
\text { personal fees from Shoppers Drug Mart, grants and } \\
\text { personal fees from IPSEN, personal fees from MT Pharma, } \\
\text { personal fees from Tilray, personal fees from Allergan, } \\
\text { personal fees from Roche, outside the submitted work. }\end{array}$ \\
\hline SO & SO has nothing to disclose. \\
\hline PP & PP has nothing to disclose. \\
\hline JWM & JWM has nothing to disclose. \\
\hline CS MD & CS has nothing to disclose. \\
\hline RT & $\begin{array}{l}\text { RT reports other funding from Allergan (Predictive Model } \\
\text { for Treatment of Spasiticity Post Stroke (Botox), chair } \\
\text { positions on data monitoring/advisory boards for studies } \\
\text { on statins for osteoporosis after SCl and exercise in SCI, } \\
\text { and medicolegal work for assessment of individuals with } \\
\text { whiplash and other musculoskeletal injuries after motor } \\
\text { vehicle accidents outside the submitted work. }\end{array}$ \\
\hline AT & AT has nothing to disclose. \\
\hline EW-N & EW-N has nothing to disclose. \\
\hline DLW & DLW has nothing to disclose. \\
\hline NX & NX has nothing to disclose. \\
\hline
\end{tabular}

members again submitted forms identifying potential conflicts of interest (Table 2).

\section{Updated literature search}

A comprehensive literature search update was conducted for articles published from November 1, 2013 to October 30, 2018, using the following scientific databases: MEDLINE, EMBASE, CINAHL, Psyclnfo, and Cochrane Library (Central Register of Controlled Trials). 'Spinal cord injury' and 'neuropathic pain' key words were searched in combination with 'intervention', 'diagnosis', and 'model of care' key words (see Appendix 1). Medical Subject Headings were used as available in each database. Searches were limited to articles published in the English language.

Inclusion/Exclusion criteria. Articles which investigated interventions for the treatment of NP in people with $\mathrm{SCl}$ were included if they met the following inclusion criteria: (1) the study population was comprised of $\geq 50 \%$ individuals with traumatic or non-traumatic $\mathrm{SCl}$, (2) the study population had NP or mixed pain, (3) there were $\geq 3$ human adult participants ( $\geq 18$ years) with $\mathrm{SCl}$ and neuropathic or mixed pain, (4) the study was conducted in a rehabilitation, outpatient, or community setting, (5) the effect of treatment on pain intensity was assessed. Articles which investigated screening or diagnostic tools or models of care for NP in people with $\mathrm{SCl}$ were also included. Articles were excluded if: (1) they involved participants with musculoskeletal pain only, (2) were conducted in an acute setting, (3) were reviews, case studies/reports, study protocols, or qualitative studies.

Article selection. After removing duplicates, articles were first screened for eligibility based on title and abstract, then based on full text, by two independent reviewers (MM, BB). Any discrepancies were resolved by a third reviewer (EL). Additionally, any other articles identified following the review of the reference lists of articles identified using the search strategy or those which were deemed to be of relevance by the expert panel were included.

GRADE assessment. The methodological quality of each article was assessed by two independent reviewers (MM, BB, EL, or SM) using a modified GRADE approach. Pain intensity was the primary outcome assessed with GRADE for articles investigating treatment modalities. If agreement on an individual GRADE level assignment was not achieved, discrepancies were resolved by a third reviewer. WG members provided input on the assessment of evidence quality during their discussions. If a change in the assigned quality of evidence was proposed, the WG voted on a potential change. If $75 \%$ or more of the panellists agreed, the GRADE assignment was adjusted.

GRADE criteria were modified in an identical process as the original 2016 CPG. Due to the generally smaller sample size in the SCI literature, the reviewers did not necessarily downgrade the quality of evidence for studies with a small sample size (see Appendix 2 GRADE scoring criteria) [6].

\section{Working group discussions}

The overall WG was divided into four smaller discussion groups that met two to four times via an online videoconferencing platform (Zoom Technologies Inc. ${ }^{T M}$ ) from January 2020 to April 2020. Each group was assigned different treatments for which new evidence was available. One group was assigned additional literature to review related to diagnosis and screening. Each group was provided with evidence tables that summarized existing literature for that treatment (if any), updated and new literature, and the modified GRADE rating. Groups reviewed the new and existing literature and provided input on the modified GRADE assignment. If there was disagreement over a particular treatment's evidence base because of conflicting study results, the WG could request a meta-analysis to attempt to resolve this conflict. New and modified recommendations were proposed by the small discussion groups for presentation to the full WG.

In accordance with the GRADE process and the AGREE II tool, the groups assigned a GRADE rating and a level of strength (strong or weak) to each proposed recommendation. Clinical experience, side-effect profile, effectiveness in other populations with NP, and any other factors that the panel considered relevant were used to determine the strength of each recommendation.

Proposed recommendations were summarized and presented to the WG for discussion at two additional meetings attended by all members. These meetings $(2-3 \mathrm{~h}$ ) were held over videoconference (Zoom Technologies, Inc. ${ }^{\mathrm{TM}}$ ) on June 15 and June 25,2020 . The WG was divided into small groups. Each group reviewed and discussed all new and modified recommendations. Groups also reviewed all 2016 treatment recommendations for which there was new evidence but no new or modified recommendations, to ensure that this was appropriate. The WG also discussed the best means with which to present and frame the recommendations. A full group discussion was held at the end of each meeting to summarize each group's key discussion points.

Proposed new and modified recommendations arising from the final meetings were summarized for presentation to the panel. The WG anonymously voted on the format of the CPG, any new/modified recommendations, GRADE ratings of the recommendations (if disagreement was voiced during the WG discussions) and the strength of new/ modified recommendations using online survey software (SurveyMonkey ${ }^{\circ}$ ). As for the 2016 CPG, recommendations achieving at least $75 \%$ agreement were adopted. Remaining treatments with new evidence were designated as "requiring further research" if appropriate and are summarized within the CPG. Existing recommendations from the 2016 CPG for which there was no new evidence remain unchanged in the current edition.

External review and endorsement. The complete drafted supplement was sent for external review in January of 2021. The quality of the guidelines was assessed by 5 external reviewers (Table 3); each of whom approved 
Table 3. External reviewers of the CanPainSCI 2021 Clinical Practice Guideline Update.

Member
Andréane Richard-Denis, MD, MSc, FRCPC
Brenda Lau, MD, FRCPC, FRCPC (Pain) founder, MM, CIPS
Neal McKinnon, MSC (PT), PhD
James Milligan, MD, CCFP
Keith Sequeira, MD, FRCPC

Table 4. Agree II Tool Scores.

\begin{tabular}{|c|c|}
\hline Scope and purpose & Mean score \\
\hline Item 1 & 7.0 \\
\hline Item 2 & 6.0 \\
\hline Item 3 & 7.0 \\
\hline \multicolumn{2}{|l|}{ Stakeholder involvement } \\
\hline Item 4 & 6.5 \\
\hline Item 5 & 6.3 \\
\hline Item 6 & 6.5 \\
\hline \multicolumn{2}{|l|}{ Rigor of development } \\
\hline Item 7 & 6.8 \\
\hline Item 8 & 6.8 \\
\hline Item 9 & 5.8 \\
\hline Item 10 & 7.0 \\
\hline Item 11 & 6.5 \\
\hline Item 12 & 6.8 \\
\hline Item 13 & 6.0 \\
\hline Item 14 & 7.0 \\
\hline \multicolumn{2}{|l|}{ Clarity of presentation } \\
\hline Item 15 & 7.0 \\
\hline Item 16 & 6.3 \\
\hline Item 17 & 7.0 \\
\hline \multicolumn{2}{|l|}{ Applicability } \\
\hline Item 18 & 6.5 \\
\hline Item 19 & 6.3 \\
\hline Item 20 & 6.0 \\
\hline Item 21 & 6.3 \\
\hline \multicolumn{2}{|l|}{ Editorial independence } \\
\hline Item 22 & 7.0 \\
\hline Item 23 & 7.0 \\
\hline \multicolumn{2}{|l|}{ Overall } \\
\hline Overall quality & 6.3 \\
\hline Recommend guideline for use? & Yes \\
\hline
\end{tabular}

the guidelines and provided feedback. Further, 4 of 5 reviewers completed the Agree II tool and provided scores on quality (Table 4). The manuscript was revised based on suggestions from these reviewers. The 2021 update to the CanPainSCl guidelines are endorsed by SCl Canada, the Canadian Association of Physical Medicine and Rehabilitation (CAPMR) SCI Special Interest Group (SIG), the CAPMR Pain SIG, the Canadian Spinal Research Organization, Spinal Cord Injury Ontario (SCI-Ontario), and Ability New Brunswick (Ability NB).

\section{RESULTS}

For the 2021 CanPainSCI CPG, the panel reviewed 46 additional articles published since the last version of the guidelines which

Professional role
Physiatrist and scientist
Anesthetist, Pain Medicine
Physiotherapist
Family Medicine
Physiatrist

\section{Affiliation}

Université de Montréal, Montreal QC, Canada

Vancouver BC, Canada

Parkwood Institute, London ON, Canada

Mobility Clinic, Waterloo ON, Canada

Western University, London ON, Canada met inclusion criteria or were deemed to be of relevance by the panel. The panel agreed on three new screening and diagnosis recommendations, and eight new treatment recommendations. No new model of care recommendations were proposed as no relevant articles were identified.

Within the treatment recommendations, seven of the 10 existing recommendations from 2016 were re-evaluated because new relevant studies published; however, no changes were made to these recommendations. Additionally, 12 new treatment options not evaluated in 2016 were assessed by the CanPainSCl group but were found not to warrant a recommendation at this time. Five treatment modalities evaluated in 2016 that did not warrant a recommendation at the time, but for which new evidence was available, were also reviewed in this version; however, no recommendations were made for these treatments.

For the screening and diagnosis recommendations, only the three new recommendations are discussed in this document. Detailed discussion on the other recommendations can be found in the 2016 version of the CanPainSCI CPG (https://www.nature. com/articles/sc201689). Given the model of care recommendations have not changed, please refer to the 2016 version (https:// www.nature.com/articles/sc201691). As there has been extensive reframing of the treatment recommendations for the 2021 update, the entire treatment guidelines are presented in this document, including recommendations and treatments requiring further research that are unchanged from 2016. Key 2021 updates are identified within the guideline text.

This update replaces the 2016 recommendations for treatment [4] and serves to supplement the 2016 screening and diagnosis recommendations [3] and 2016 recommendations for model systems of care [5]. Table 5 provides an updated list of all CanPainSCl recommendations.

\section{Screening and diagnosis recommendations}

For screening and diagnosis, three new recommendations were developed as part of the 2021 CanPainSCI CPG update to supplement existing 2016 recommendations (Table 5). The existing recommendations remain "expert opinion" as in the 2016 CPG.

Listing of 2021 new screening and diagnosis recommendations. 1.6. The Spinal Cord Injury Pain Instrument (SCPI)) and Neuropathic Pain Symptom Pain Inventory (NPSI) can be used to supplement the diagnosis of neuropathic pain for people with spinal cord injury.

1.10 The NPSI can be used to supplement the assessment and documentation of neuropathic pain.

1.15 The NPSI can be used to supplement the evaluation of treatment response.

Level of Evidence: High

Strength of Recommendation: Strong

2021 clinical considerations. Three new studies were identified that addressed screening and diagnosis of NP after $\mathrm{SCl}$ [7-9]. Two cross-sectional studies of moderate quality evaluated the SCIPI. One study compared the SCIPI to a clinical assessment of NP [8], 

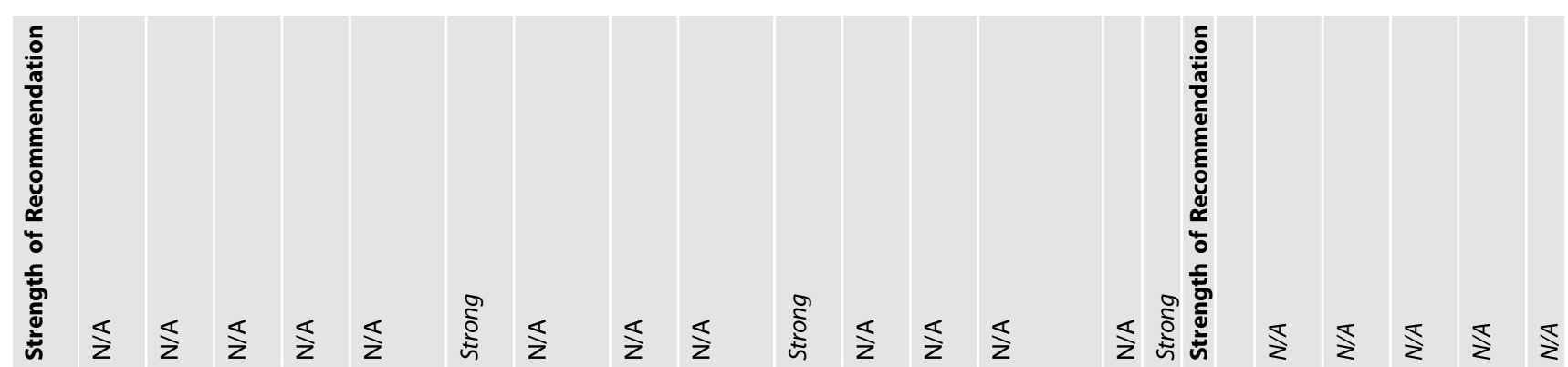

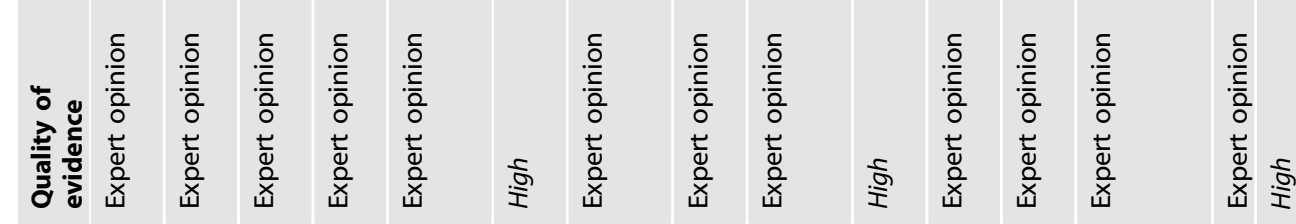

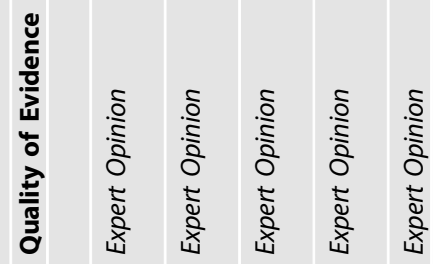

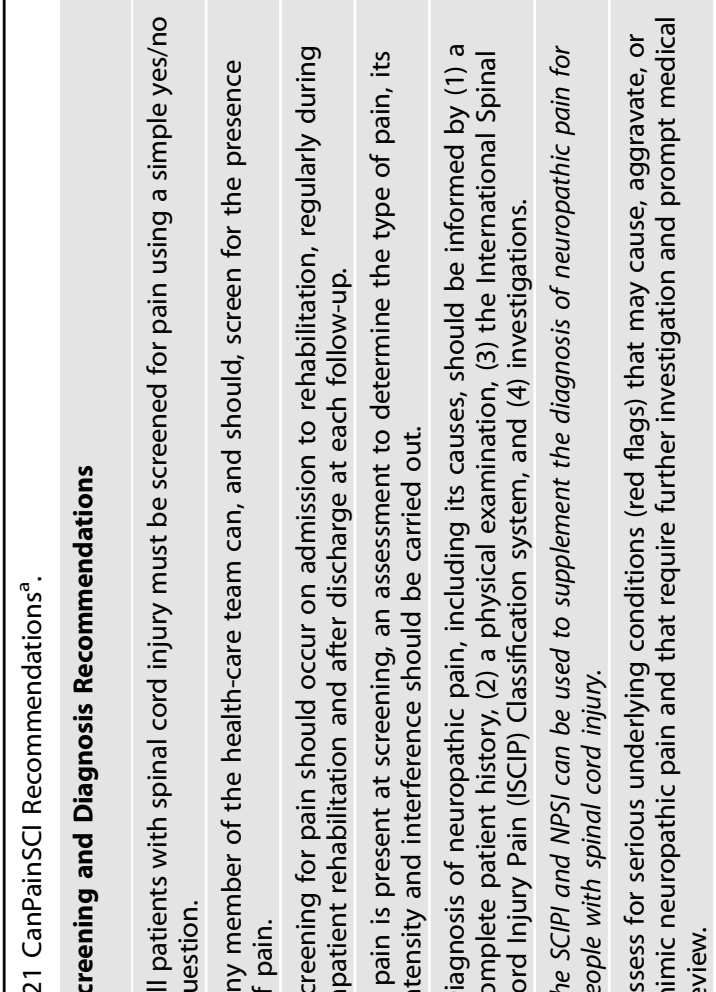

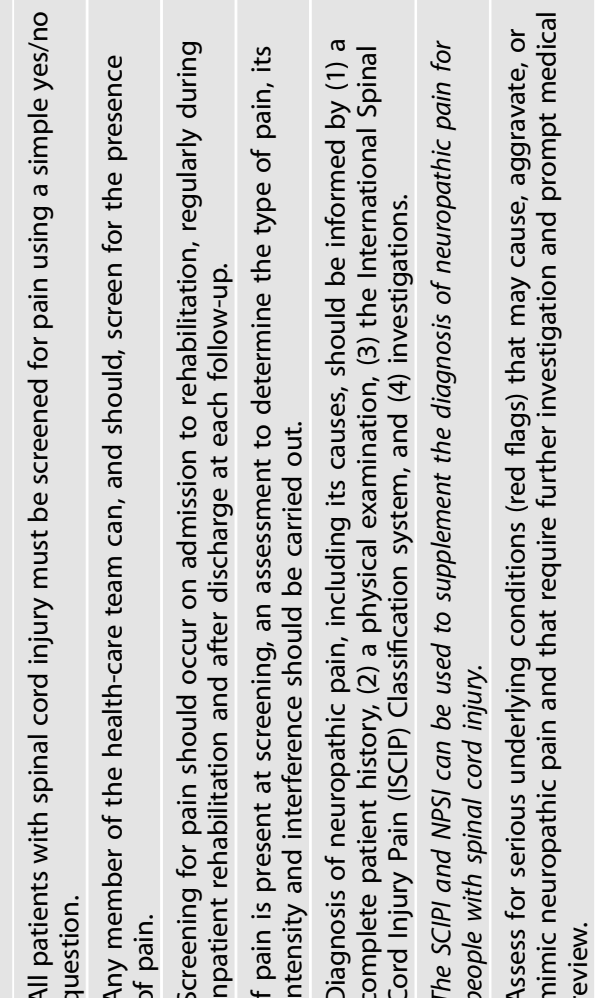

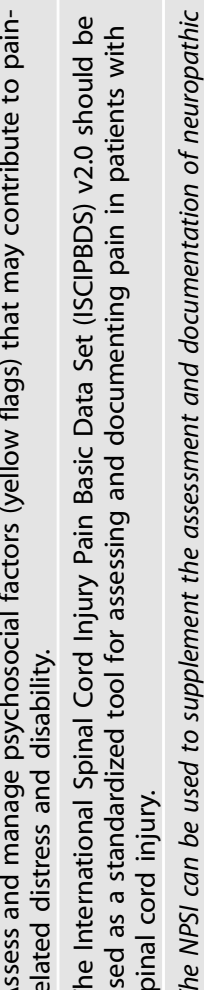

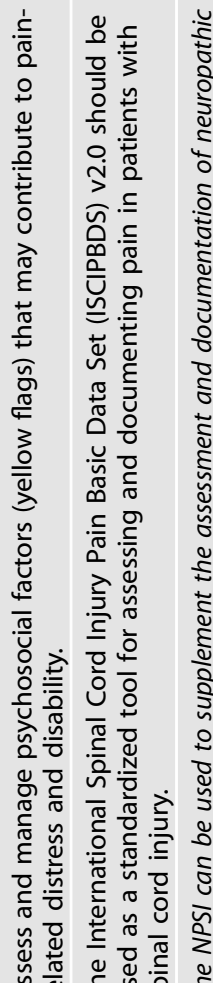

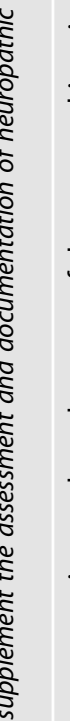

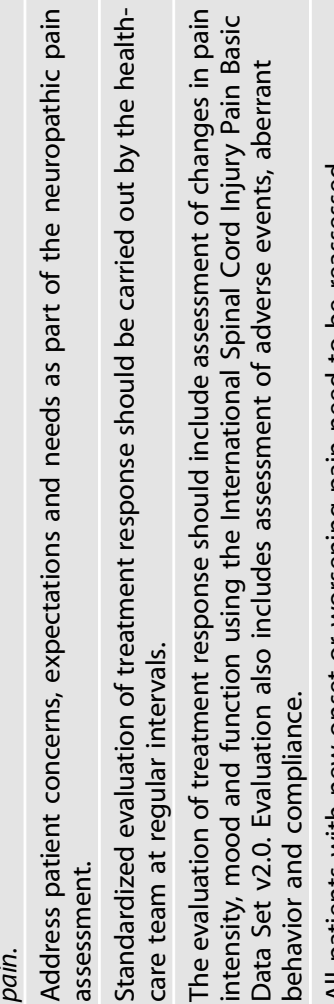

告

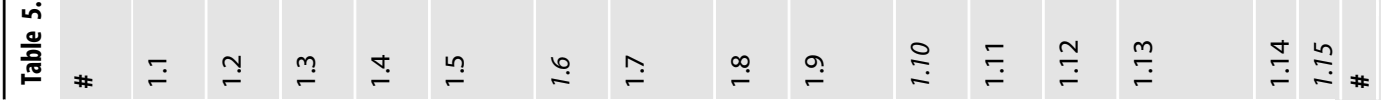

\section{का है।}

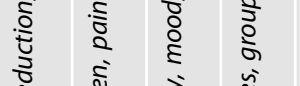

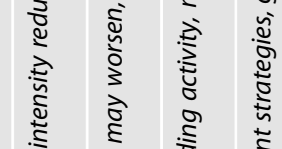

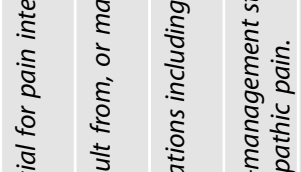

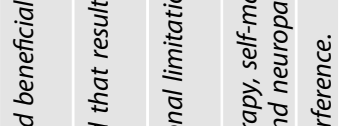

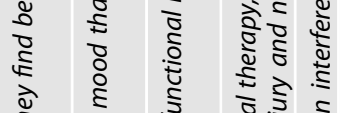

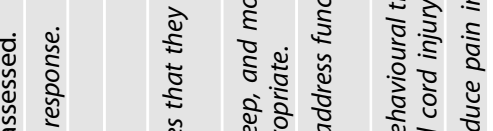
竞 : वृ

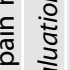
ำ ำ ฐ है $\frac{2}{\frac{2}{5}}$ co 畓 表

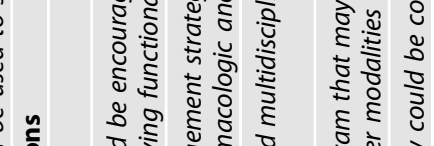

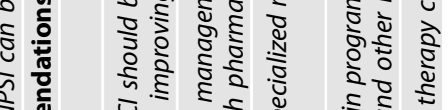

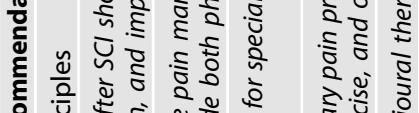

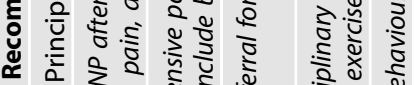

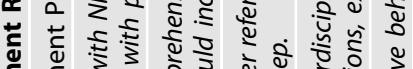

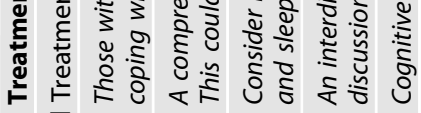
뜌

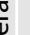
ร के है के है है 竎.

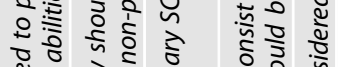

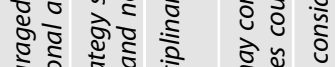
先- 4 2 d 


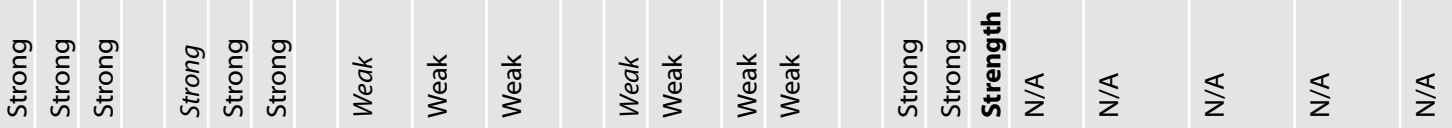

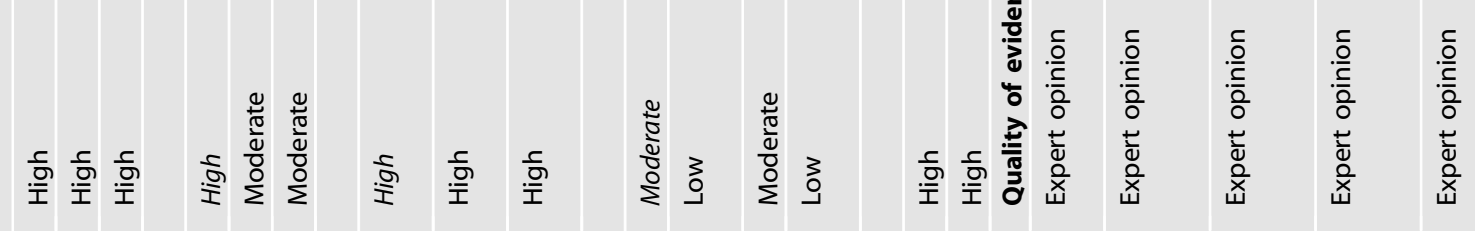

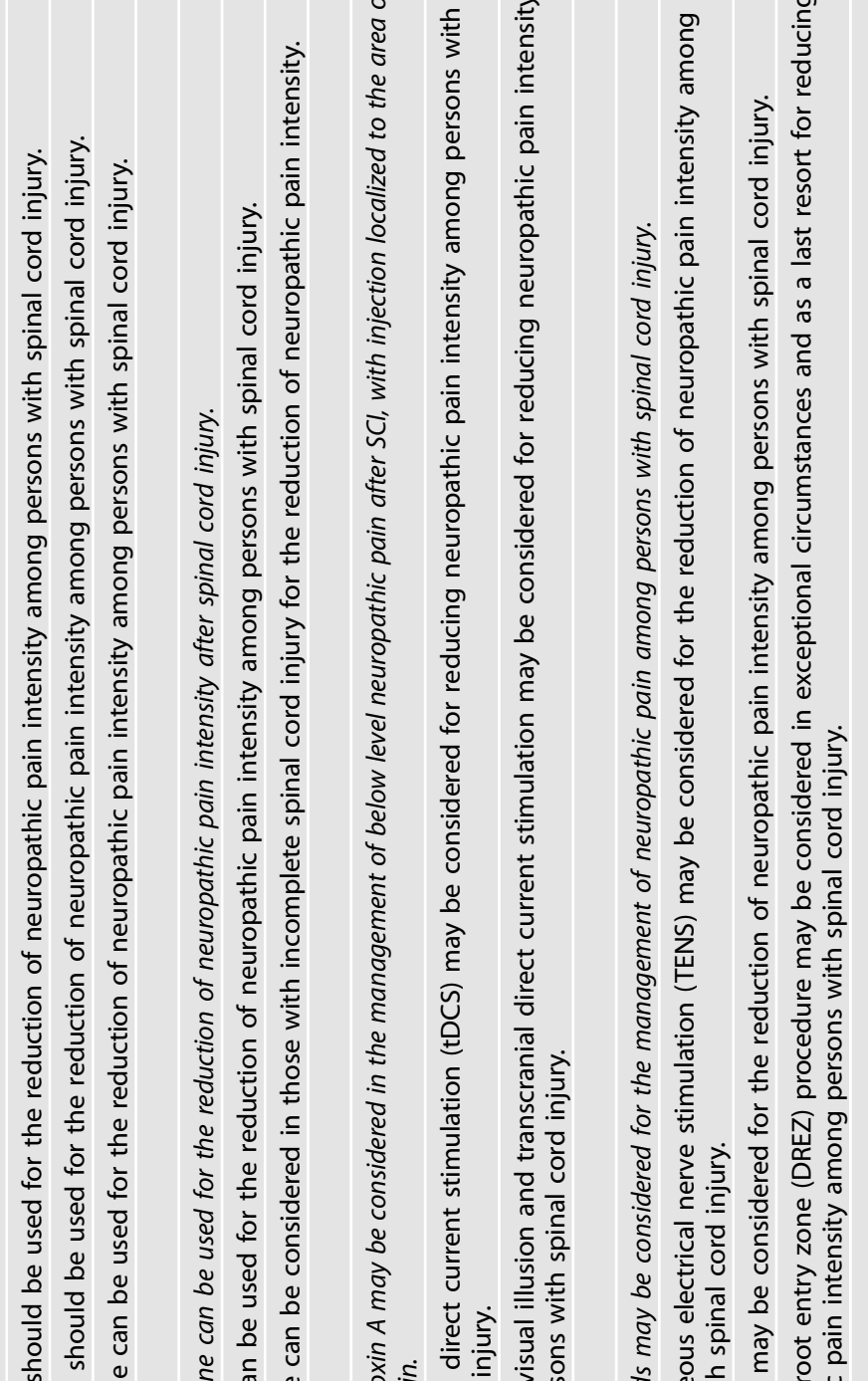

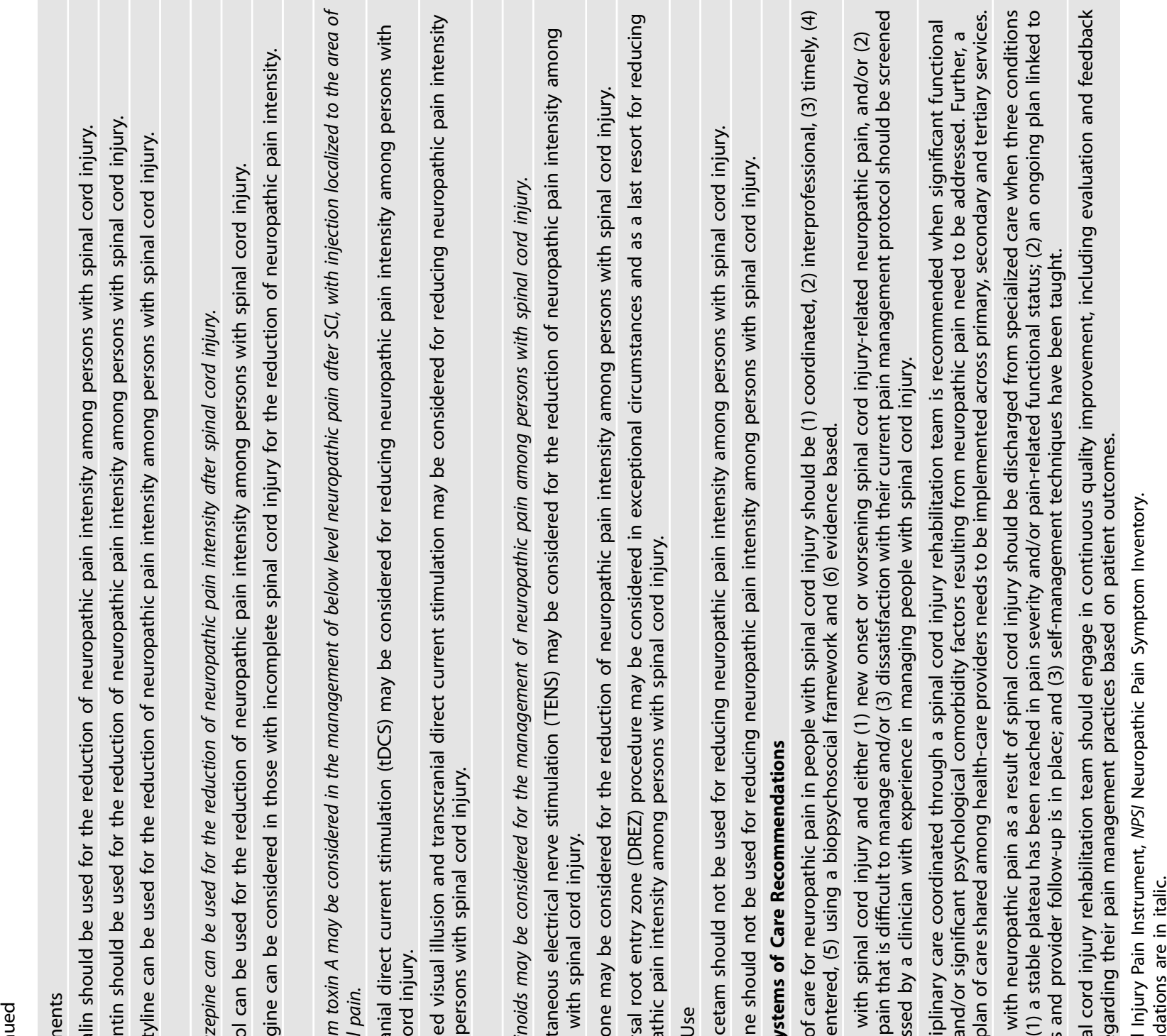

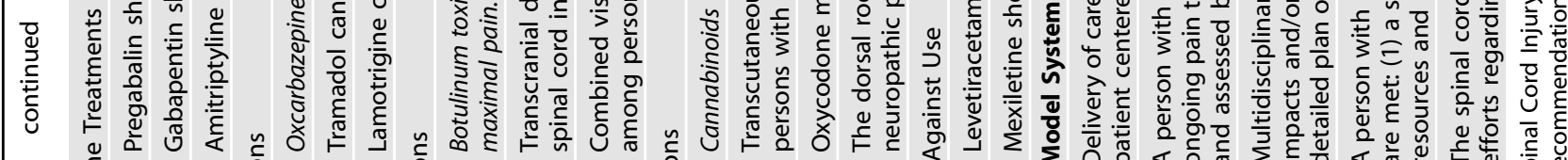

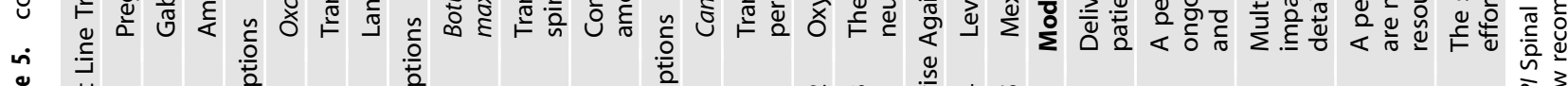

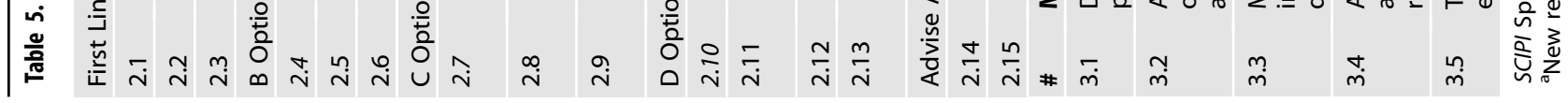


554

with sensitivity of $78 \%$, specificity of $73 \%$, and diagnostic accuracy of $76 \%$ when at least two out of four SCIPI items highly correlated with NP were endorsed (electrical/shock like; pins/needles, tingling; skin feels hot/burning, cold?; occurs in insensate areas). A second study evaluated a German language version of SCIPI and the painDETECT questionnaire using the International Association for the Study of Pain (IASP) grading system, with strong convergent construct validity [7].

A 2020 study [9] of the NPSI was proposed by members of the WG for evaluation. Although this 2020 study fell outside the formal literature search window identified in the current CPG, the WG agreed that it was important to consider. There were very few studies on these types of tools in the SCl literature and the WG felt that it may provide important context and guidance for NP screening and diagnosis. This study evaluated the NPSI against a numeric rating scale for pain severity, and the Multidimensional Pain Inventory pain severity and perceived support subscales in those with moderate to severe NP after SCl, with the NPSI demonstrating good psychometric properties in this population. A test-retest reliability (intraclass correlations) of $0.65-0.73$ for NPSI subscores and 0.79 for total NPSI; internal consistency with Cronbach's alpha of 0.70 ; and construct validity with positive correlations between pain intensity NRS and the pain severity subscale of the MPI $(r>0.4)$ were described [9].

As all three studies are preliminary with relatively small sample sizes, they are not sufficient to change or replace the current tools recommended for screening, making a diagnosis, and evaluating treatment response in NP after $\mathrm{SCl}$. However, they provide additional tools and criteria to consider within these domains.

\section{TREATMENT RECOMMENDATIONS 2021 key changes}

General treatment principles and treatment recommendation classification. The WG agreed that it was important to formalize key treatment principles within the treatment recommendations to inform clinical practice. Some of these principles were presented in the 2016 version of the CPG, although were not specific recommendations, in contrast to the 2021 version.

In order to assist CPG users and clinicians managing NP after $\mathrm{SCl}$, two key changes were introduced to the treatment recommendations: the addition of five recommendations that are "general treatment principles", and a major restructuring of the classification of treatment options.

The consensus panel discussed the optimal way to present the recommendations to support and facilitate with implementation of the CanPainSCI CPG into clinical practice. Clearer definitions and guidance regarding the use of different lines of treatment (i.e. first, second, third, and fourth) were found to be necessary.

The panel agreed that the first-line treatments pregabalin and gabapentin should always be considered initially. While amitriptyline is also first-line, its use needs to be carefully considered given the potential side effects of the medication (see section on firstline treatments).

For second-, third- and fourth-line treatments, the panel agreed a hierarchical approach to these treatments was not necessarily appropriate as the overall body of evidence for non-first-line treatments is limited. The panel did not feel it was necessary or appropriate to have exhausted second-line treatments; for example, before initiating a third-line treatment. Clinician selection between second to fourth line treatments could be based on other relevant factors, including patient preference and shared decision-making, tolerability, clinician experience, side effect profile, and accessibility. One exception is the dorsal root entry zone procedure (DREZ), which given its invasiveness as a treatment and significant risk of side effects, should only be considered as a last resort if it is used at all.

The panel emphasized it was, however, still important to acknowledge that certain treatment options had a higher evidence basis and/or strength of recommendation from the expert panel than others (e.g., second-line vs. third- or fourth-line treatments). Thus, a distinction should still be present within the CPG between different groups of treatment options. Given that a hierarchical approach was not used for these treatment groupings, second- to fourth-line treatments were reclassified as "B options" (formerly second-line), "C options" (formerly third-line) and "D options" (formerly fourth-line). The criteria for classifying a treatment within one of these groupings were the same as for second/third/fourthline treatments, and were based on GRADE/strength of the recommendation as follows (GRADE; strength of recommendation): B options (High/Moderate; Strong); C options (High/Moderate; Weak); D options (Moderate/Low; Weak). The phrasing of recommendations was also standardized to reflect the assessments of the expert panel on the different treatment groupings. B option recommendations are phrased as "can be used" for NP following $\mathrm{SCl}$, while $\mathrm{C}$ and $\mathrm{D}$ option recommendations are phrased as "may be considered" for NP following SCl.

Although a hierarchy of treatment options was not used, the consensus panel agreed that classifying and phrasing the recommendations in this way would provide adequate clarity and information to the CPG user regarding the panel's assessment and evaluation of different treatment options. Figure 1 presents the treatment recommendations as a diagram; Table 5 presents a full text listing all treatment recommendations.

\section{General treatment principles}

2021 new recommendations. G1. Those with NP after SCl should be encouraged to pursue self-management strategies they find beneficial for pain intensity reduction, coping with pain, and improving functional abilities.

Type of evidence: expert opinion.

2021 clinical considerations. The consensus panel acknowledges that the overall body of evidence for treatment of $\mathrm{NP}$ after $\mathrm{SCl}$ is limited. There may be self-management strategies that persons living with NP after $\mathrm{SCl}$ find beneficial for coping with their pain and improve functioning. These strategies may include hypnosis, exercise, yoga, massage, stretching, pacing education, peer support, and acupuncture. Evidence for these modalities, however, may be limited or non-existent [10-12]. If a person with $\mathrm{SCl}$ experiences improvement in NP and/or its impact on their daily life with these treatments and the treatments are acceptable to both the person receiving treatment and their health care provider, they should pursue the strategies that they find helpful.

G2. A comprehensive pain management strategy should address issues that relate to, or may worsen, pain due to activity, sleep and mood interference. This could include both pharmacologic and non-pharmacologic strategies as appropriate.

Type of evidence: expert opinion.

2021 clinical considerations. Sleep and mood are important aspects of chronic pain management in general. Sleep and mood can be worsened by pain, and vice versa. It is important to address sleep and mood with both pharmacologic and non-pharmacologic management strategies; clinical guidelines for the management of insomnia and depression can be consulted if needed [13-16]. It should be noted that some medications used for NP management in $\mathrm{SCl}$ may improve sleep (e.g., gabapentin, pregabalin, and amitriptyline). This may be a useful effect in some cases but would also require monitoring for excessive daytime sedation.

G3. Consider referral to an $\mathrm{SCl}$ rehabilitation expert for specialized interdisciplinary management of functional limitations and associated issues of mood, activity and sleep.

Type of evidence: expert opinion.

2021 clinical considerations. NP intensity may not significantly change despite best available management and may continue to 


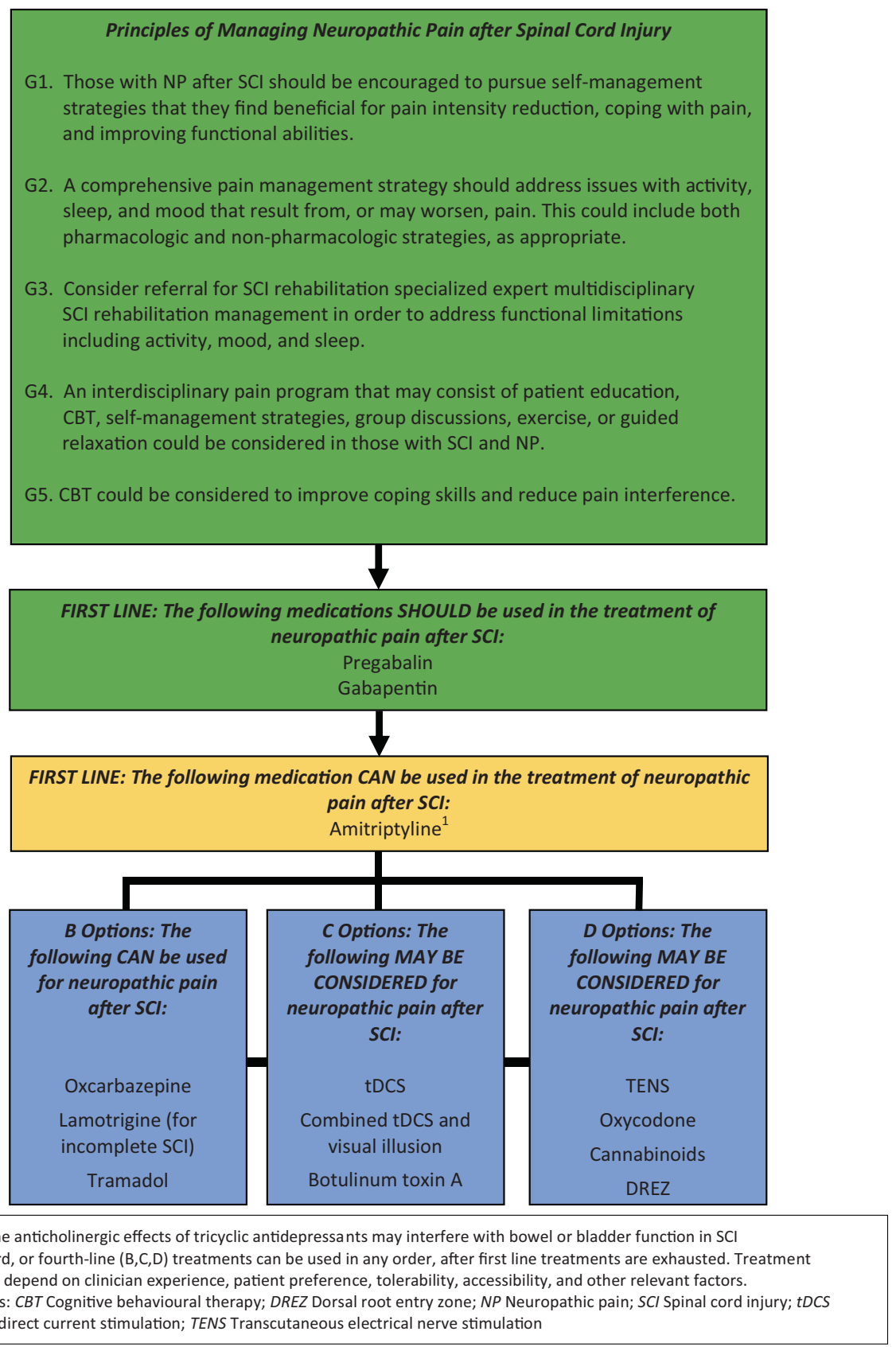

Fig. 1 Principles of managing neuropathic pain after spinal cord injury. ${ }^{1}$ Note that the anticholinergic effects of tricyclic antidepressants may interfere with bowel or bladder function in SCl. *Second, third, or fourth-line $(B, C, D)$ treatments can be used in any order, after first line treatments are exhausted. Treatment selection will depend on clinician experience, patient preference, tolerability, accessibility, and other relevant factors. CBT Cognitive behavioral therapy, DREZ Dorsal root entry zone, NP Neuropathic pain, SCI Spinal cord injury, tDCS Transcranial direct current stimulation, TENS Transcutaneous electrical nerve stimulation.

significantly interfere with daily function. Assessment and management by an interdisciplinary team may provide improvements in function through adaptive strategies (including adaptive equipment) and education. Due to the specialized nature of $\mathrm{SCl}$ care and the unique needs of this population, referral to an $\mathrm{SCl}$ rehabilitation expert should be considered to address functional concerns associated with NP.

G4. An interdisciplinary pain program that may consist of patient education, cognitive.

behavioral therapy (CBT), self-management strategies, group discussions, exercise, and other modalities could be considered in those with $\mathrm{SCl}$ and NP.

Type of evidence: expert opinion.
2021 clinical considerations. Depending on the resources and expertise available in different clinical contexts, referral to a specialized interdisciplinary pain program could also be considered. Resources that are available within an interdisciplinary pain program may not be available in a specialized $\mathrm{SCl}$ rehabilitation clinic, and vice versa. Based on local factors, the needs of the person experiencing pain after $\mathrm{SCl}$, and the clinical judgment of the provider, there may be benefit in accessing an interdisciplinary pain program and/or management by a specialized $\mathrm{SCl}$ interdisciplinary team.

G5. CBT could be considered to improve coping skills and reduce pain interference.

Type of evidence: expert opinion. 


\section{1 clinical considerations}

5 articles [17-21] were identified that evaluate the impact of CBT on pain intensity; only one pre-post study [17] reported decreased pain intensity immediately following treatment and at 12-month follow-up (although no changes were seen at 6 and 9 months). Although the available evidence has not clearly supported the use of CBT to reduce $\mathrm{NP}$ intensity after $\mathrm{SCl}$, it may reduce interference from NP after $\mathrm{SCl}$, with associated improvements in sleep and mood [17-21]. The panel considers CBT an important aspect of a comprehensive management plan for those with NP after $\mathrm{SCl}$, as pain intensity reduction can be elusive, especially if first-line options are not successful. CBT provides a means of potentially improving quality of life despite the presence of ongoing NP. This treatment could also be offered in conjunction with first-line treatments to improve coping and function, or as an option for first-line treatment if the patient prefers non-pharmacologic management, or if there is a contraindication to other first-line options.

\section{Specific treatment options}

The following sections present first-line treatments, B, C and D options, and "advise against use" recommendations made by the WG. Within each category, the information is organized as follows:

(1) New recommendations: Any new recommendations for the 2021 CPG are listed first, with clinical considerations that provide context for these recommendations immediately following the recommendation (listed as "2021 Clinical Considerations").

(2) Existing recommendations: Unchanged recommendations from the 2016 CPG are listed under this heading. "Clinical Considerations" accompanying each recommendation were included in the 2016 CPG to provide additional context and relevant clinical information. These "Clinical Considerations" are provided in this update as they appeared in 2016 ("2016 Clinical Considerations"). Additional context relating to any newly identified studies are provided in the section "2021 Update". Although the WG did not formally evaluate effects on pain interference, these outcomes were discussed if those outcomes were available in the literature. Effects on pain interference are noted in the "2021 Update" section as appropriate, as they were not specifically included in the 2016 version.

\section{First-line treatments}

First-line treatments have a high GRADE of evidence and a strong recommendation from the panel.

New recommendations. No new first-line treatment recommendations were proposed.

\section{Existing recommendations.}

\section{Recommendation 2.1}

Pregabalin should be used for the reduction of neuropathic pain intensity among persons with spinal cord injury.

Quality of evidence High

Strength of recommendation Strong

2016 clinical considerations. Pregabalin is recommended as the first choice of first-line medications, as it has the strongest evidence of any treatment modality in below-level NP: all studies demonstrate a significant reduction in pain intensity. Pregabalin studies used larger sample sizes than most treatment studies for $\mathrm{SCl}$-related NP and rigorous methodology. Two high-quality randomized placebo-controlled trials (RCTs) $[22,23]$ and one moderate-quality placebo-controlled RCT [24], which was downgraded based on wide confidence intervals around numbers needed to treat, comprise the evidence base for pregabalin. When defining successful treatment of individual patients as a $50 \%$ reduction in pain level, the NNT for these 3 trials was 7.1 [22], 7.0 [25], and 3.3 [24]. All studies focused on NP and measured pain intensity. One trial studied a mixed population that included stroke patients $(n=19)$, but a subgroup analysis was performed for the group with SCI [24]. A pharmaceutical company funded two pregabalin RCTs [22, 23]. Pregabalin studies used flexible dosing between 150 and $600 \mathrm{mg} /$ day. Adverse effects include somnolence, dizziness, and edema which were usually of mild-tomoderate intensity and transient $[22,23,26]$.

2021 update. Two low/very low quality crossover studies [27, 28] did not demonstrate a difference between gabapentin and pregabalin for pain intensity reduction ( $n=30$ [29]; $n=28$ [27]). Another high quality crossover study [30] $(n=55)$ showed pregabalin was significantly more effective than oxcarbazepine for those with evoked pain character of allodynia and heat hyperalgesia, but no difference in pain reduction between pregabalin and oxcarbazepine for those with evoked pain with character of electrical, burning, pricking, and numbness, or in those without evoked pain. A metaanalysis involving members of the SC from 2016 demonstrated significant decreases with pregabalin on pain (standardized mean difference: $1.71 \pm 0.13 ; 95 \% \mathrm{Cl}, 1.458-1.965 ; P<0.001$ ). sleep interference, anxiety and depression [31]. No changes to the existing recommendation were proposed based on the newly evaluated studies.

\section{Recommendation $\mathbf{2 . 2}$}

Gabapentin should be used for the reduction of neuropathic pain intensity among persons with spinal cord injury.

Quality of evidence High

Strength of recommendation Strong

2016 clinical considerations. Gabapentin is recommended as the next choice when pregabalin is not an option or has been proven ineffective, as the evidence supporting gabapentin in SCl-related NP is not as strong as that for pregabalin. The body of evidence for gabapentin in SCl-related NP contains three randomized trials, two of which found no significant difference between gabapentin and placebo [32,33], although one trial [33] found a trend toward pain intensity reduction with gabapentin $(n=7)$. The third study found gabapentin significantly reduced NP [34]. Two observational case series included only patients with SCl-related NP. One found a reduction in NP intensity [35], and the other found a reduction in (general) pain intensity [36]. An observational study of gabapentin in patients with $\mathrm{SCl}$ and different durations of symptoms, which included patients with cauda equina, found a significant reduction in the mean pain intensity score after treatment with gabapentin [37]. Maximum gabapentin doses in clinical trials ranged from 1800 to $3600 \mathrm{mg} /$ day, and the major adverse events reported were dizziness and somnolence [32-34].

2021 update. In the 2016 version, outcomes of reviewed studies were conflicting, but a meta-analysis performed as part of the data review indicated a significant decrease in pain with gabapentin (standardized mean difference $=1.20 \pm 0.16 ; 95 \% \mathrm{Cl}, 0.88-1.52 ; P$ $<0.001$ ) [31]. Additionally, in 2016, the panel agreed that further study was required to establish that gabapentin and pregabalin are interchangeable within the $\mathrm{SCl}$ population; it was noted that other CPGs for the management of central or peripheral NP consider both pregabalin and gabapentin first-line therapy. Two crossover trials were reviewed as part of the 2021 update, one of low quality [28] and the other of very low quality [27]. These studies reported similar reductions in pain intensity between 
pregabalin and gabapentin. Although these studies were not superior in quality to those previously included, they provide further evidence that both gabapentin and pregabalin reduce pain and pain interference in those with $\mathrm{SCl}$ and NP. The WG noted anticonvulsants, including gabapentin and pregabalin, do not impair motor recovery. These medications may have the most beneficial effect on motor recovery if given early.

Gabapentin may have positive effects on sleep; sleep interference scores improved after 8 weeks of treatment with gabapentin in one pre-post study, whether pain was present for less than, or equal to and greater than, 6 months [37].

\section{Recommendation $\mathbf{2 . 3}$}

Amitriptyline can be used for the reduction of neuropathic pain intensity among persons with spinal cord injury.

Quality of evidence

High

Strength of recommendation Strong

2016 clinical considerations. If pregabalin and gabapentin have been ineffective, amitriptyline is recommended; less evidence exists for the efficacy of amitriptyline than for the gabapentinoids. A meta-analysis of four antidepressant RCT for the management of SCl-related NP found that these agents were effective in reducing NP [38]. Two RCTs that studied amitriptyline had conflicting results $[32,39]$. One small study of patients with NP $(n=22)$ found amitriptyline more effective than active control (diphenhydramine) and gabapentin [32]. This study also found that NP was more likely to improve in patients with depressive symptoms. The second study of patients with NP ( $n$ $=51)$ and musculoskeletal pain $(n=33)$ found no significant difference between amitriptyline and control (benzotropine mesylate) [39]. Amitriptyline is typically used to treat NP at a dose of $25-150 \mathrm{mg} /$ day [40]. Treatment is usually initiated at 10-25 mg daily. In the Rintala et al. study, which demonstrated amitriptyline efficacy in the treatment of SCl-related NP, nearly all participants reached the target dose of $50 \mathrm{mg}$ three times a day [32]; these findings suggest that lower doses may be less effective. Adverse effects of TCAs include anticholinergic side effects, sedation, and cardiotoxicity, which mandate caution in the $\mathrm{SCl}$ population. Within other pain populations, secondary amine TCAs (nortriptyline and desipramine) tend to have similar efficacy but better tolerability than tertiary amines (amitriptyline and imipramine). There is a lack of evidence specific to patients with SCl-related NP for both secondary and tertiary amine TCAs.

2021 update. A new randomized trial of moderate quality [41] was reviewed $(n=147)$ that compared amitriptyline to lamotrigine. No significant difference was seen between these treatments, although both amitriptyline and lamotrigine demonstrated statistically significant reductions in overall NP. The duration of this trial was relatively short ( 3 weeks), so it is not possible to comment on side effects that may be more evident with prolonged use. Additionally, the majority of participants in this study were younger ( $74 \%$ were $18-40$ years old) and may therefore better tolerate amitriptyline. The panel continues to emphasize that amitriptyline can cause significant issues in those with $\mathrm{SCl}$ given its anticholinergic properties; for this reason, the recommendation for amitriptyline is that it "can be used" for the management of NP after $\mathrm{SCl}$, rather than "should be used".

\section{"B" options}

These options were previously classified as "second-line" treatments. They represent either high or moderate evidence on GRADE and a "strong" strength of recommendation from the panel.
New recommendations.

Recommendation 2.4

Oxcarbazepine can be used for the reduction of neuropathic pain intensity after spinal cord injury.

Quality of evidence High

Strength of recommendation Strong

2016 clinical considerations. A single high-quality randomized crossover study [30] compared oxcarbazepine and pregabalin. For those with evoked pain present, both medications demonstrated significant effect for electrical pain, burning pain, pricking pain, numbness, allodynia, and pressure analgesia. Oxcarbazepine did not have a significant effect on heat hyperalgesia, but pregabalin did. For those in the evoked pain absent group, both treatments demonstrated significant effect for electrical pain, burning pain, pricking pain, and numbness. As described in the pregabalin 2021 update section, there was no difference between oxcarbazepine and pregabalin in those with evoked pain present for electrical pain, burning pain, pricking, and numbness, however, pregabalin was significantly more effective than oxcarbazepine for those with allodynia and heat hyperalgesia. No significant difference was seen between treatments in those without evoked pain. Those with psychiatric diseases were excluded, so pharmacodynamic drug-drug interactions (particularly with antidepressant medications that can also cause the side effect of hyponatremia) for this subpopulation within $\mathrm{SCl}$ cannot be defined. When the severity of side effects associated with oxcarbazepine is compared to lamotrigine (which was already a " $\mathrm{B}$ " option) the side effect profile of oxcarbazepine is favorable. When considering this and the results of the crossover study, the panel agreed that oxcarbazepine could be used for NP after SCl. Despite the decreased severity of side effects associated with oxcarbazepine in the anticonvulsant class, the prescriber should be aware of several medication risks. There is a risk of hyponatremia (2-3\%) especially within the first 3 months [42]; concomitant use with a selective serotonin reuptake inhibitor (SSRI) or diuretic medications requires close monitoring as these class of medications can also induce hyponatremia. Monitoring of serum sodium levels may be required at baseline and periodically while on treatment when patients have pharmacodynamic risk factors for hyponatremia. As a weak inducer of CYP3A4, those on oral contraception should be counseled that the medication could reduce the effectiveness of their contraceptive and additional contraceptive precautions (e.g., condoms) may be desired.

\section{Existing recommendations.}

\section{Recommendation $\mathbf{2 . 5}$}

Tramadol can be used for the reduction of neuropathic pain intensity among persons with spinal cord injury.

Quality of evidence

Moderate

Strength of recommendation Strong

2016 clinical considerations. A single randomized, placebocontrolled trial found a significant reduction in pain intensity with tramadol compared with placebo, but the evidence quality was downgraded because of wide confidence intervals [43]. The Canadian Guideline for Safe and Effective Use of Opioids for Chronic NonCancer Pain is a useful resource for general information on opioid management and prescription considerations [44]. Although tramadol is not a scheduled drug in Canada at the time of writing this CPG, Health Canada is currently reviewing tramadol for a potential scheduling change and is listed as a Schedule IV drug in the United States. The maximum daily dosage of tramadol is $400 \mathrm{mg}$ [40]. Common adverse effects are sedation, nausea and constipation. Twelve out of thirteen participants in the Norrbrink and Lundeberg 
[43] trial withdrew because of adverse medication events. A slight increase in the risk of serotonin syndrome can be seen when tramadol is combined with other serotonergic drugs such as SSRIs, serotonin norepinephrine reuptake inhibitors, TCAs, etc [45].

2021 update. No new studies were identified for review. The WG reviewed pain interference descriptions in the literature, and no significant changes in pain interference were noted with tramadol compared to placebo [43].

\section{Recommendation 2.6}

Lamotrigine can be considered in those with incomplete spinal cord injury for the reduction of neuropathic pain intensity.

Quality of evidence Moderate

Strength of recommendation Strong

2016 clinical considerations. Evidence for the efficacy of lamotrigine has been demonstrated only in patients with an incomplete $\mathrm{SCl}$. As a result, lamotrigine is recommended as second-line therapy only in this subpopulation. One randomized placebo-controlled trial showed lamotrigine significantly reduced the intensity of NP for patients with incomplete SCl; the evidence quality was downgraded because of wide confidence intervals [46]. Lamotrigine was titrated to a maximum dose of $400 \mathrm{mg}$ per day [46]. Common adverse effects were dizziness, somnolence, headache, and rash. It should be noted that lamotrigine has a black box warning issued by the United States Food and Drug Administration for serious skin rashes, including Stevens-Johnson Syndrome.

2021 update. One additional randomized longitudinal study [41] of moderate quality evaluated the comparative effect of lamotrigine and amitriptyline. This study included both patients with complete and incomplete $\mathrm{SCl}$, and although both amitriptyline and lamotrigine demonstrated statistically significant reductions in overall NP, there were no significant between-group differences for overall NP at any follow-up time point. Follow-up was within a relatively short time period of 3 weeks, so the long-term effectiveness of these treatments was difficult to ascertain from this study. The majority (76\%) of participants in this study were classified as an American Spinal Injury Association Impairment Scale (AIS) grade A lesion. The expert panel therefore discussed the potential use of lamotrigine in those with complete $\mathrm{SCl}$. As follow-up was for a short period and treatment was unblinded, the panel decided there was not enough new evidence to support a change in the recommendation. The panel concluded the effect of lamotrigine on NP in those with complete $\mathrm{SCl}$ requires more research.

\section{"C" options}

These options were previously classified as "third-line" treatments. They represent either high or moderate evidence on GRADE and a "weak" strength of recommendation from the panel.

\section{New recommendations.}

Recommendation 2.7

Botulinum toxin A may be considered in the management of belowlevel neuropathic pain after $\mathrm{SCl}$, with injection localized to the area of maximal pain.

Quality of evidence

High

Strength of recommendation

Weak

2021 clinical considerations. One RCT of high quality has been conducted to evaluate the effect of botulinum toxin A on NP intensity in patients with $\mathrm{SCl}$ [47]. This study found significant reductions in pain intensity compared to placebo at 4 and 8 weeks following injection for below-level (but not at-level) NP. The sample size in this study was relatively small, and the findings of this study require replication. Further research is required to determine whether other factors, such as, level and completeness of injury, may affect treatment efficacy. The panel also recognizes access to this treatment may be limited as it is an off-label indication, and may present a barrier to obtaining drug coverage. Given the evidence for botulinum toxin A is preliminary for NP, the expert panel felt that only a weak recommendation was appropriate.

\section{Existing recommendations.}

Recommendation $\mathbf{2 . 8}$

Transcranial direct current stimulation (tDCS) may be considered for reducing neuropathic pain intensity among persons with spinal cord injury.

$\begin{array}{ll}\text { Quality of evidence } & \text { High } \\ \text { Strength of recommendation } & \text { Weak }\end{array}$

2016 clinical considerations. tDCS is recommended as " $C$ " therapy for patients with SCl-related NP based on four RCTs. Three studies found a significant reduction in pain intensity with tDCS compared to sham control [48-50]. One of these studies found a significant improvement in continuous pain on the last day of treatment, and paroxysmal pain at follow-up, but no significant reduction in overall pain intensity [50]. A fourth study did not find a significant difference between tDCS and sham control [51]. A prospective controlled trial that found a significant reduction in pain intensity, compared to sham control, was upgraded because of small confidence intervals and the inclusion of an intention-totreat analysis [52]. In our prior meta-analysis of the five studies we found a positive effect for tDCS on pain intensity $(S M D=0.510 \pm$ $0.202 ; 95 \% \mathrm{Cl}, 0.114-0.906 ; p=0.012$ ) [53]. tDCS was, however, given a weak strength of recommendation, as the effects were not maintained over time and the panel felt it was more appropriate to trial pharmacological therapies first, in accordance with other NP management guidelines and extensive clinical experience with those treatments in NP secondary to various etiologies. Minor side effects of tDCS include skin irritation, which can be minimized by preparing electrodes with saline and the skin with electrode cream and by increasing current gradually. Another side effect, phosphene, which is the visual perception of a brief flash of light, can be avoided with correct electrode placement (not placed too close to the eye).

2021 update. One RCT [54] of low quality provides additional supporting evidence for NP intensity reduction following tDCS in comparison to sham control, while one RCT crossover of moderate quality did not find a significant difference in NP intensity between active and sham tDCS treatments [55]. An RCT crossover of very low quality examined a single session of active or sham tDCS, neither of which resulted in reductions in pain intensity following treatment [56]. One low quality pre-post study found a significant decrease in pain intensity following tDCS treatment at 2-week follow-up, although this was not sustained at 3 weeks [57]. From a pain interference perspective, tDCS improved mood, general activity and the ability to get around on the last day of treatment (day 14) [50].

A meta-analysis of all nine studies found a positive short-term effect for tDCS on pain intensity, indicating a beneficial effect of treatment that is limited in duration. The expert panel noted that there is variability in treatment protocols for tDCS in different studies, which makes generalizability difficult. No changes were made to the recommendation at this time. 


\section{Recommendation $\mathbf{2 . 9}$}

Combined visual illusion and transcranial direct current stimulation may be considered for reducing neuropathic pain intensity among persons with spinal cord injury.

$\begin{array}{ll}\text { Quality of evidence } & \text { High } \\ \text { Strength of recommendation } & \text { Weak }\end{array}$

2016 clinical considerations. An RCT in SCl-related NP found a significant reduction in pain intensity after treatment compared to control illusion, visual illusion in isolation, and tDCS in isolation [50]. An observational study of a cohort that included individuals with neuropathic and other types of pain found a nonsignificant improvement in pain intensity after treatment [58]. The main side effects of this combined therapy included mild headache and fatigue [50].

2021 update. No new studies were identified for review. Evaluating previously included studies from a pain interference perspective, combined tDCS and visual illusion resulted in improvements on various aspects of the Brief Pain Inventory at various timepoints after initiating treatment when compared to tDCS alone, visual illusion alone, or placebo, at various time points [50].

\section{"D" options}

These options were previously classified as "fourth-line" treatments. They represent either moderate or low evidence on GRADE and a "weak" strength of recommendation from the panel.

\section{New recommendations.}

\section{Recommendation $\mathbf{2 . 1 0}$}

Cannabinoids may be considered for the management of neuropathic pain among persons with spinal cord injury.

Quality of evidence Moderate

Strength of recommendation Weak

2021 clinical considerations. Two studies have been conducted to evaluate the effect of cannabinoids on NP intensity in patients with $\mathrm{SCl}[59,60]$. One $\mathrm{RCT}$ crossover of moderate quality investigated two different strengths of vaporized cannabis (i.e., 2.9 or $6.7 \%$ delta-9-tetrahydrocannabinol), and found that pain intensity was significantly lower for both compared to placebo, with no difference in analgesic effect between the active doses [59]. The follow-up period for outcome measurement in this study was only $7 \mathrm{~h}$. There was a lack of graded analgesic response with higher doses. Blinding was a concern in this study given that psychoactive effects had a dose dependent response. An earlier pilot RCT of low quality did not find a difference in NP intensity reduction between dronabinol and active control (diphenhydramine) groups [60].

The panel also discussed evidence for the effectiveness of cannabinoids (including nabiximols) in other central NP conditions besides SCl. The expert panel agreed that the adverse effect profile for cannabinoids was preferable to that of oxycodone and other opioids. Risks of tolerance and hyperalgesia associated with opioids also made the option of cannabis potentially advantageous as a treatment choice. Therefore, the expert panel chose to include a specific recommendation regarding cannabis for $\mathrm{NP}$ after $\mathrm{SCl}$, although further research regarding its effects is still needed.

\section{Existing recommendations.}

\section{Recommendation $\mathbf{2 . 1 1}$}

Transcutaneous electrical nerve stimulation (TENS) may be considered for the reduction of neuropathic pain intensity among persons with spinal cord injury.

Quality of evidence

Low

Strength of recommendation Weak

2016 clinical considerations. One prospective controlled observational study has evaluated the effect of TENS in patients with SCl-related NP [61]. This trial found no significant difference between high-frequency and low-frequency TENS. An early (1975) observational case series found a pain intensity reduction with TENS for two of 11 patients [62]. The evidence quality of this study was downgraded because of a lack of confidence intervals and description of methods, and a potential for bias.

It is important to consider the short duration of action for relief of pain with TENS when contemplating use of this modality. In addition, lack of long-term follow-up precludes any discussion of the prolonged efficacy of TENS. Few side effects are associated with TENS, although patients have reported increased pain intensity and muscle spasm [63]. The WG did not include TENS among the therapies without specific recommendations because of a lack of long-term follow-up, however, the relatively innocuous side effects of TENS make this therapy appropriate for a therapeutic trial in refractory cases.

An additional consideration is electrode placement. Although evidence is limited, the utility of TENS when electrodes are placed in insensate areas has been demonstrated. Recent trials have used placement of electrodes at the level of injury in an area with preserved or intact sensibility $[62,63]$.

2021 update. Three studies provide additional supporting evidence for NP intensity reduction following treatment with TENS. One RCT crossover study of moderate quality compared TENS with visual illusion [64]. A significant reduction in pain intensity was found after TENS application for 2 weeks, while there was no significant decrease in pain intensity after 2 weeks for visual illusion. On the BPI, TENS significantly decreased the effect of pain on mood, sleep and relationships with others; visual imagery improved walking ability [64]. In another RCT of moderate quality, low frequency TENS was found to significantly reduce pain intensity compared to baseline after 10 days of treatment, while no significant effect was observed with sham TENS [63]. This study was originally excluded in the 2016 version, but upon review, it was found to fit criteria for the 2021 update and was reviewed again for this update. A pre-post study of very low quality showed a significant reduction in pain intensity compared to baseline following 8 weeks of treatment with high frequency TENS [65]. A meta-analysis of four studies found a positive effect for TENS on pain intensity [61, 63-65]. The expert panel determined that the new evidence would not significantly strengthen or weaken the previous recommendation or affect it negatively. Thus, this recommendation is unchanged.

\section{Recommendation $\mathbf{2 . 1 2}$}

Oxycodone may be considered for the reduction of neuropathic pain intensity among persons with spinal cord injury.

Quality of evidence

Moderate

Strength of recommendation Weak 
2016 clinical considerations. Oxycodone is an oral opioid that has been assessed in SCl-related NP. One observational study, which showed a significant reduction in pain intensity after 3 months of treatment, had its quality of evidence upgraded because confidence intervals were provided and only patients with NP were included [66].

Long-term opioid use exposes individuals to unique risks including possible problems with drug tolerance and dose escalation, physical dependence, opioid induced hyperalgesia, endocrinopathy and potential for misuse/addiction [67]. Typical opioid adverse effects include sedation, nausea, vomiting, constipation and dry mouth [44]. Constipation in particular can be problematic in people with $\mathrm{SCl}$ who may have pre-existing neurogenic bowel changes. Oxycodone is around approximately one and a half times as potent as morphine. The potential adverse effects and issues associated with oxycodone, and opioids in general, led the panel to assign a weak strength of recommendation. The panel recommends additional research into the use of opioids as a class in patients with SCl-related NP. It is likely reasonable to use opioids other than oxycodone, and the Canadian Guideline for Safe and Effective Use of Opioids for Chronic Non-Cancer Pain should be used to guide the use of medications in this class [44].

2021 update. No new studies were identified for review.

\section{Recommendation 2.13}

The DREZ procedure may be considered in exceptional circumstances and as a last resort for reducing neuropathic pain intensity among persons with spinal cord injury.

Quality of evidence

Low

Strength of recommendation

Weak

2016 clinical considerations. Evidence of benefit for the DREZ procedure exists, but the risk of the procedure does not justify its use beyond exceptional circumstances. The available evidence supporting the DREZ procedure is based on observational studies or case series in SCl-only populations [68-72], with one study including patients with cauda equina [70]. A prospective-controlled observational trial found a reduction in pain intensity with the DREZ procedure and greater efficacy in below-level pain [68]. An observational study found a reduction in pain intensity after the DREZ procedure [70]. Three observational case series found the DREZ procedure reduced pain intensity [70-72]. Risks associated with the DREZ procedure include paresis, neuropathy or radiculopathy, ataxia, sensory loss, and a variety of surgical complications, such as persistent incisional site pain, cerebrospinal fluid leak, wound infection, subcutaneous hematoma, and bacteremia [69, 71].

2021 update. Two pre-post studies of very low quality provide additional supporting evidence for NP intensity reduction following the DREZ procedure. One study found pain relief 2 weeks and 3 months after the procedure, as well as at longterm follow-up (average of 36.1 months) [73], while the other study found complete or near-complete below-level NP relief following the DREZ procedure at follow-up periods ranging from 1.5 to 11 years [74]. The risk for DREZ remains the same, and the level of evidence is unchanged from the previous version of the guidelines at "low". The recommendation was unchanged in this version.

\section{Advise against use}

The studies for these treatment options showed no effect or benefit in the $\mathrm{SCl}$ population, and therefore recommendations advise against their use.

\section{Recommendation 2.14}

Levetiracetam should not be used for reducing neuropathic pain intensity among persons with spinal cord injury.

Quality of evidence

High

Strength of recommendation

Strong

2016 clinical considerations. A prospective RCT performed in a population with SCl-related NP comparing levetiracetam to placebo found no significant difference between the two treatments [75].

2021 update. No new studies were identified.

Recommendation $\mathbf{2 . 1 5}$

Mexiletine should not be used for reducing neuropathic pain intensity among persons with spinal cord injury.

Quality of evidence High

Strength of recommendation Strong

2016 clinical considerations. A prospective, placebo-controlled $\mathrm{RCT}$ in a population of patients with SCl-related NP found mexiletine was not significantly more effective than placebo in reducing pain intensity [76].

2021 update. No new studies were identified.

\section{Therapies requiring further research}

For various reasons, the WG did not make specific recommendations for some treatments that were previously evaluated for the original 2016 CPG. Insufficient evidence for benefit, studies with conflicting results and insufficient data to perform meta-analyses, lack of enough studies to provide pooled data, lack of evidence of long-term effect or follow-up, evidence of positive effect in populations other than $\mathrm{SCl}$, or low-quality studies with negative results may have resulted in a "requires further research" designation from the WG. The only treatment that moved from "requires further research" to a specific recommendation was cannabinoids, which is now a " $\mathrm{D}$ " option.

Additionally, the WG identified 14 new treatment options, not evaluated in the 2016 version, as requiring further research. Descriptions of these treatments are provided in this section. The WG also re-evaluated treatments that were previously designated as requiring further research in the 2016 CPG if new studies were available for review. These included hypnotic suggestion, transcranial magnetic stimulation, intravenous (IV) ketamine, visual illusion, and acupuncture. Updated descriptions for these treatments are provided below; the panel did not make new recommendations for these management options. No new studies were identified for exercise, spinal cord stimulation, massage, osteopathy, duloxetine, IV lidocaine, IV alfentanil, IV clonidine and morphine, or IV morphine. The previous descriptions of these treatments from the 2016 version of the guidelines are included within this document to provide a single, updated resource.

New treatments-further research required. The treatments in this section were identified as requiring further research and were not previously reviewed in 2016 .

Intermittent normobaric hyperoxia. A single moderate quality RCT ( $n=62$ ) found that a group receiving $4 \mathrm{~h}$ of pure oxygen had significant improvement in the mean visual analogue scale score at 14 days compared to a group receiving $4 \mathrm{~h}$ of air (control) and $3 \mathrm{~h}$ of air plus $1 \mathrm{~h}$ of pure oxygen (group A) [77]. No long-term effect (day 
30 and day 60) was seen, although data was not provided. Given the lack of long-term benefit, no recommendation was made.

Neurofeedback training. Three studies of very low quality (one RCT crossover, and two pre-post studies) evaluated neurofeedback training. The pre-post studies demonstrated some benefit, although sample sizes were small $[78,79]$. The RCT crossover demonstrated no benefit of a single session of neurofeedback training on pain intensity [56]. Evidence was insufficient to make a recommendation at this time.

Anti-inflammatory diet. A single moderate quality RCT showed a significant group versus time interaction on the anti-inflammatory diet for the sensory component of the self-reported NP questionnaire [80]. Post hoc analyses revealed a significant reduction in sensory scores in the anti-inflammatory diet group from baseline to 1 month and 3 months. The WG noted that the study suggests a possible relationship between changes in inflammatory mediators and sensory scores; findings should be replicated in a larger study.

Ultramicronized palmitoylethanolamide (PEA-Um). One highquality RCT showed no benefit with ultramicronized palmitoylethanolamide compared to placebo [81]. Although there was no evidence to suggest that it should be used, the WG determined there was not enough evidence to make a recommendation against its use. Timing of administration may be important, and earlier administration post injury may demonstrate a more favorable outcome. The WG noted PEA-um has a positive effect in other NP populations, and would therefore benefit from additional study.

Breathing-controlled electrical stimulation (BreEStim). One highquality [82] and one moderate-quality [83] RCT crossover study demonstrated a treatment benefit. The WG was concerned regarding the resource burden of the treatment. The findings were considered too preliminary for a recommendation to be made.

BreEStim $+t D C S$. One moderate quality RCT crossover did not find a difference between combined tDCS and BreEStim treatment and BreEStim treatment alone [55]. In consideration with studies examining BreEStim alone, this study did not significantly change the overall quality of evidence to warrant a recommendation for BreEStim.

Neurotensin (CGX-1160). The WG agreed one low-quality study [84] with a sample size of four was not sufficient to justify a recommendation.

Autologous mesenchymal stromal cells. Four pre-post studies of very low quality of autologous mesenchymal stromal cells (MSC) demonstrated mixed results, with three studies demonstrating decreased pain up to 10 months post MSC transplantation [85-87], and one study demonstrating no significant difference in pain intensity 6 months post treatment [88]. Additional studies are needed to confirm benefit.

Neuromuscular electrical stimulation + carbamazepine. One prospective controlled study of very low quality investigating combined neuromuscular electrical stimulation and carbamazepine did not demonstrate additional benefit for the combined treatment over the group that received carbamazepine alone [89]. The WG concluded a recommendation could not be made either way based on one very low quality study.

Intrathecal baclofen. A moderate-quality RCT demonstrated improvement in NP pain intensity after intrathecal baclofen 4 and $8 \mathrm{~h}$ post treatment compared to the placebo group [90]. There was also significant improvement in pain interference with mood, general activity, moving around, enjoyment of life, ability to work and perform daily tasks, and social relationships in the treatment group. Additional evidence, including long-term follow-up, is required for a recommendation.

Meditation. One crossover trial of very low quality evaluating meditation and other non-pharmacologic treatment modalities against sham $\mathrm{tDCS}$ showed a significant reduction in pain intensity for meditation compared to sham tDCS [56]. Follow-up measurement of pain intensity, however, was only evaluated up to $10 \mathrm{~min}$ after treatment. Given the very low quality of the study and the short duration of follow-up, no recommendation was made by the WG at this time.

TENS + gabapentin. A RCT of very low quality described significantly decreased pain intensity after 10 days of treatment with a combination of TENS and gabapentin compared to sham TENS and gabapentin [91]. There was insufficient evidence for a recommendation.

Overground bionic ambulation. One very low quality pre-post study of three participants evaluated overground bionic ambulation [92]. There is insufficient evidence for a recommendation to be made.

Venlafaxine. A single RCT found no significant improvement in pain intensity or interference outcomes for venlafaxine compared to placebo [93]. The WG voted on a possible recommendation against the use of venlafaxine for NP after SCl. 63\% of WG members agreed that further research into this treatment would be appropriate, rather than advising against use. $6 \%$ of WG members suggested a potential fourth-line role for venlafaxine. The WG noted that although this study suggested no specific effect on central NP for venlafaxine, it may have a role in mixed neuropathic and nociceptive presentations; additional research is required to replicate these findings.

2021 updates for previously evaluated treatments-further research required. The following section lists treatments requiring further research that were previously evaluated in 2016, and for which additional studies were identified for the 2021 CanPainSCI CPG update. These treatments continue to require additional research. The previous description for these treatments from the 2016 version is included, with a separate section describing the 2021 update.

Hypnotic suggestion. 2016: An RCT found a reduction in intensity of SCl-related NP after treatment $(p<0.01)$, but the evidence quality was downgraded because of a lack of confidence intervals [94].

2021 update: An additional crossover trial of very low quality evaluated hypnosis and other non-pharmacologic treatment modalities (e.g., meditation, described in previous suggestion) against sham tDCS [56]. There was significant reduction in pain intensity following this treatment, although follow-up was only continued for $10 \mathrm{~min}$ post treatment. The new study was not sufficient to change the requirement for further research into hypnotic suggestion.

Transcranial magnetic stimulation (TMS). 2016: Three RCTs in SClrelated NP compared the effect of TMS with sham therapy [95-97]. Two of these trials found no significant difference in reduction in pain intensity $[95,96]$. The evidence quality of the third trial, which found a significant improvement in pain intensity after treatment, was downgraded because of wide confidence intervals [97].

2021 update: Two additional RCTs were identified. One RCT demonstrated no effect [29], while the other demonstrated a 
positive effect for up to 4 weeks only [98]. For pain interference, there was no significant difference between real and sham TMS on the BPI [96]. The WG voted on a potential recommendation for TMS, but the consensus threshold for a new recommendation was not met $(61.5 \%$ agreed but $75 \%$ was needed to pass this as a new recommendation); additional study with longer-term follow-up is needed. The logistics of providing this treatment was also raised as a concern.

Acupuncture. 2016: One study showed no significant effect on chronic pain intensity in patients with $\mathrm{SCl}$-related pain or chronic musculoskeletal pain; non-responders were all from the central pain population [99]. In another study, eight of fifteen patients with SCl-related NP responded to acupuncture [100]. A retrospective observational case series of patients with traumatic or nontraumatic $\mathrm{SCl}$ found a significant improvement in pain for bilateral, symmetric, burning, or constant pain compared with unilateral, asymmetric, atypical, or intermittent pain [101]. Studies of acupuncture suffer from a lack of standardization of process or procedure delivery and practice principles, and evidence for effectiveness is inconclusive. Additional studies are needed to clarify the benefit of using this modality.

2021 update: A moderate quality crossover trial assessed battlefield acupuncture (BFA) against a waitlist control [102]. A significantly larger decrease in pain severity (NRS scores) was observed in the battlefield acupuncture group compared to the control group. The WG expressed concerns regarding the lack of a true control group (waitlist control group), and a specific methodology for delivering treatment (battlefield acupuncture). There was also a higher baseline pain intensity in the treatment group as compared to the control group. A second very low quality pre-post study examining percutaneous electrical nerve stimulation was also reviewed [103]. This study demonstrated significantly decreased pain intensity on the NRS at 8 and 18 weeks post treatment. One study [104] suggested that acupuncture may also have an effect on pain interference with activities of daily living at 7.5 weeks, but not at 3 months. The WG again discussed the large variation in practice and techniques for acupuncture, with the lack of a standardized protocol being problematic despite some evidence for effect. Some members noted there is evidence in the literature, and extensive practical experience, that suggests the treatment is safe. The WG voted on a possible recommendation for acupuncture. A slight majority (56\%) agreed that acupuncture should be a recommendation, but this did not reach threshold for inclusion (75\%).

Visual illusion. 2016: One RCT in patients with SCl-related NP found a significant reduction in overall pain intensity compared with a control illusion on the last day of treatment, but this change did not persist and was not evaluated at follow-up [50]. An observational study that found an insignificant reduction in pain intensity with the intervention was downgraded because of a lack of information on sequence generation, wide confidence intervals, and a very small sample size $(N=5)$ [105]. Another observational study found a significant increase in pain intensity after treatment in comparison with a control illusion [106].

2021 Update: One moderate quality crossover study [64], one low quality RCT [107], one low quality pre-post study [32] and two additional very low quality studies $[108,109]$ were reviewed by the WG. The WG considered the new evidence in conjunction with the 2016 studies. Interventions differed widely between studies, which made comparison difficult. Some studies had no longitudinal evaluation, and it was difficult to evaluate long-term effect overall. The WG also raised questions regarding the mechanism of this treatment, and whether visual illusion had an impact on neuroplasticity, or was useful to serve only as a distraction from pain. The WG did vote on a potential recommendation for visual illusion, but only $61.5 \%$ agreed that it should be a recommendation, which was lower than the required threshold. Further research was therefore required before a recommendation could be made.

IV ketamine. 2016: Two RCTs of IV ketamine in SCl-related NP found a significant reduction in pain intensity $[110,111]$. The evidence quality of one study was downgraded because of the absence of a power calculation and an unclear protocol [110]. The second study, a double-blind crossover study of nine patients with central dysesthetic pain after $\mathrm{SCl}$, evaluated ketamine and alfentanil compared with placebo (normal saline) [111]. Ketamine significantly reduced the intensity of continuous pain and allodynia compared with placebo. As the treatment response was only measured before and after infusion, the duration of response is uncertain.

2021 Update: No new study on IV ketamine was done, although a topical ketamine pre-post study of five people was evaluated [112]. Ketamine continues to require additional research in SCI NP.

\section{Previously evaluated treatments with no new studies-further research required}

The following section lists treatments requiring further research that were evaluated in 2016, for which no additional studies were identified in the 2021 CanPainSCI CPG update. The 2016 description for these treatments is included in this section.

Exercise. One RCT of pain in patients with $\mathrm{SCl}$ found a reduction in the pain perception score in the treatment group compared with the control group after 3 months $(F[1,27]=4.99, p=0.03)$ [113]. However, the evidence quality of the study was downgraded because of the following: an unclear protocol; lack of specification of the type of pain, blinding, confidence intervals, and power calculation; and potential bias of control participants.

Spinal cord stimulation. A case series with a mixed pain population of patients with $\mathrm{SCl}$ presented no statistically significant data on pain intensity reduction [114].

Massage. A prospective-controlled trial, which included a comparison between acupuncture and massage, found that massage did not produce a significant reduction compared with acupuncture in SCl-related NP intensity [100]. No evidence was found on efficacy of massage on its own.

Osteopathy. An RCT found a $16 \%$ reduction in the perception of SCl-related NP during treatment but not at later time points [115]. No significance was reported for this result, and the evidence quality of this study was downgraded because of a lack of randomization process description, blinding and confidence intervals.

Duloxetine. One RCT showed no significant difference in reduction in intensity of NP between duloxetine and placebo in patients with $\mathrm{SCl}$ or stroke, although a trend was seen toward a decrease in the mean pain score with duloxetine, demonstrating the potential for benefit [116]. A good evidence base exists for the effectiveness of duloxetine in treating peripheral NP in other populations [117]. The CPG for the prevention and management of diabetic neuropathy recommends duloxetine as an option for the treatment of NP in this population [118]. Doses of 60 and 120 $\mathrm{mg}$ appear to be effective in reducing the intensity of peripheral NP. Nausea is a typical side effect. Clinically insignificant increases in blood pressure can occur while hepatotoxicity is rare [40].

IV lidocaine. IV lidocaine has demonstrated benefit in three wellconducted RCTs of SCl-related NP $[110,119,120]$. One of these trials also included patients with stroke [120]. Two of the studies found a significant reduction in pain intensity with IV lidocaine compared with placebo $[119,120]$, whereas the third found no significant difference [110]. The evidence quality of one study was downgraded because of a lack of power calculation and an 
unclear protocol [110], while another was downgraded because of a lack of explanation of the randomization process and large confidence intervals [119]. The studies with a positive result used lidocaine $5 \mathrm{mg} / \mathrm{kg}^{-1}$ over $30 \mathrm{~min}[119,120]$, whereas the study with a negative result used lidocaine $2.5 \mathrm{mg} / \mathrm{kg}^{-1}$ over $40 \mathrm{~min}$ [110]. Light-headedness was a common adverse effect. As the duration of benefit for IV lidocaine is very short, this treatment modality should only be considered in specific circumstances where a short duration of effect is desired.

IV alfentanil. A single double-blind cross-over study of nine patients with central dysesthetic pain after $\mathrm{SCl}$ evaluated alfentanil and ketamine compared with placebo (normal saline) [111]. Alfentanil significantly reduced the intensity of continuous pain compared with placebo $(p=0.01)$, allodynia compared with placebo and wind-up-like pain compared with placebo. As the response of continuous pain to therapy was only measured before and after the infusion, the duration of response is uncertain. The IV mode of administration of alfentanil makes this therapy a shortterm management option with a short duration of effect.

Intrathecal clonidine. One RCT that compared intrathecal clonidine with placebo (saline) found no statistically significant difference in reduction of pain intensity in patients with $\mathrm{SCl}$ related pain, and the evidence quality of the study was downgraded because of a lack of description of the randomization process or patient allocation [121].

Intrathecal clonidine and morphine. One double-blind cross-over study of 15 patients that compared intrathecal administration of clonidine, morphine, clonidine plus morphine and saline (placebo) found a significant reduction in pain intensity only for the combination of intrathecal morphine and clonidine compared with placebo ( $p=0.0084)$ [121]. Two of four patients with at-level pain and five of 14 patients with below-level pain responded to the combination, but no significant difference was found between the groups. As a significant correlation was seen between pain relief and drug concentrations in the cervical cerebrospinal fluid, consideration should be given to administering the agents above the level of injury to ensure adequate penetration of cervical cerebrospinal fluid. The duration of response is uncertain but is assumed to be $24 \mathrm{~h}$, as patients were crossed over to the next therapy the following day.

IV morphine. One small, double-blind, placebo-controlled, crossover study of IV morphine in patients with SCI- or stroke-related NP found no significant difference in spontaneous pain between placebo and IV morphine but a 90 -min post-injection reduction in allodynia with morphine [122]. The evidence quality of the study was downgraded because of the lack of power calculation. All patients subsequently received oral sustained-release morphine, but the titration schedule was not well defined, and the study used haloperidol, an uncommon treatment for opioid-induced nausea. Overall, the results of this study were inconclusive for a benefit of IV morphine.

\section{DISCUSSION}

These guidelines represent the most up-to-date version of the CanPainSCl CPG. As in the 2016 CPG, the primary outcome for treatment options evaluated through the GRADE process was pain intensity. The WG is aware this is not the only relevant outcome, nor is it the most important outcome in all cases. Although not formally evaluated within this version of the CPG, the WG considered other outcomes (e.g., function, pain interference, etc.) in their discussions. Future editions of the CPG will formally assess other relevant pain outcomes using GRADE.
A limitation of the 2016 CPG was the lack of high-quality studies; it was recognized by the 2016 panel that further research is required for most treatment options including those that were developed into recommendations. In the intervening time since the initial 2016 CanPainSCl guidelines, the overall study quality on which recommendations are based has not drastically improved. Of the 43 new articles reviewed in the treatment category, all but five articles were considered moderate to very low in quality.

A case could certainly be made that the evidence is too weak for many of the CanPainSCI recommended treatments to be presented as specific recommendations. The CPG WG panel discussed this issue at length. The WG agreed that although the overall evidence base remains weak, it is unacceptable for those with NP after $\mathrm{SCl}$, and for clinicians, to have no guidance on management. Although study quality is limited, extensive work has been done within NP and $\mathrm{SCl}$, and the consensus of the CanPainSCl panel represents a best effort to summarize existing work and to develop a framework to guide management decisions. High quality trials of NP treatments after $\mathrm{SCl}$ can be challenging to produce given the low prevalence of $\mathrm{SCl}$, which is further complicated by variations in etiology, level, and severity. As such, the WG noted that significant improvements in the overall quality of the evidence base could take years, if not decades, to achieve. It is, therefore, important to have a document that provides a framework for NP management after $\mathrm{SCl}$, and the panel agreed on the importance of the guidelines to serve as a reference point for clinicians and to identify areas for research for $\mathrm{NP}$ after $\mathrm{SCl}$.

The CanPainSCl panel made the decision to restructure the classification of treatment recommendations from first to fourth line to the current "first-line", " $B$ ", " $C$ ", and " $D$ " system, to account for the inherent challenges of working with a limited evidence base. An additional general recommendation regarding the pursuit of self-management strategies that those with SCl find successful (G1) was also included as a response to the limited evidence that underlies many treatment options.

\section{Update}

The process of updating the CanPainSCI CPG was discussed by the panel. While formal updates are intended to occur every 4-5 years, the panel noted it may be less onerous to conduct smaller updates more frequently, and would keep the CPG continually upto-date. A living guidelines process was discussed, with updates and reviews to be performed on a yearly basis, involving smaller, rotating groups within the WG. The full panel would review any changes at the 4-5-year point as scheduled, and issue a formal update of the CPG at that time. We expect the living guideline process to begin at the end of 2021.

\section{Applicability}

The next steps for implementation of the CPG will be refinement of existing clinical algorithms to allow easier uptake at point-ofcare. Alternative means of disseminating the guidelines, including via phone app, are in development. Appendix 3 provides a visual summary of the algorithm in development for the screening, diagnosis, and treatment of NP following $\mathrm{SCl}$. While measuring the impact of the CPG on specific, quantifiable pain outcomes is challenging given the considerable flexibility in selecting treatment options, a project is underway to implement the CanPainSCl CPG within a local context to identify barriers and facilitators for a broader national implementation strategy.

\section{REFERENCES}

1. Loh E, Guy SD, Mehta S, Moulin DE, Bryce TN, Middleton JW, et al. The CanPain $\mathrm{SCl}$ Clinical Practice Guidelines for Rehabilitation Management of Neuropathic 
Pain after Spinal Cord: introduction, methodology and recommendation overview. Spinal Cord. 2016:54:S1-6.

2. Brouwers MC, Kho ME, Browman GP, Burgers JS, Cluzeau F, Feder G, Fervers B, Graham ID, Grimshaw J, Hanna SE, Littlejohns P, Makarski J, Zitzelsberger L. for the ANSC. AGREE II: Advancing guideline development, reporting and evaluation in healthcare. Can Med Assoc J. 2010;182:E839-842.

3. Mehta S, Guy SD, Bryce TN, Craven BC, Finnerup NB, Hitzig SL, et al. The CanPain $\mathrm{SCl}$ Clinical Practice Guidelines for Rehabilitation Management of Neuropathic Pain after Spinal Cord: screening and diagnosis recommendations. Spinal Cord. 2016;54:S7-S13.

4. Guy SD, Mehta S, Casalino A, Côté I, Kras-Dupuis A, Moulin DE, et al. The CanPain SCI Clinical Practice Guidelines for Rehabilitation Management of Neuropathic Pain after Spinal Cord: Recommendations for treatment. Spinal Cord. 2016;54:S14-S23.

5. Guy SD, Mehta S, Harvey D, Lau B, Middleton JW, O'Connell C, et al. The CanPain $\mathrm{SCl}$ Clinical Practice Guideline for Rehabilitation Management of Neuropathic Pain after Spinal Cord: recommendations for model systems of care. Spinal Cord. 2016;54:S24-7.

6. Guyatt G, Oxman AD, Akl EA, Kunz R, Vist G, Brozek J, et al. GRADE guidelines: 1. Introduction - GRADE evidence profiles and summary of findings tables. J Clin Epidemiol. 2011;64:383-94.

7. Franz S, Schuld C, Wilder-Smith EP, Heutehaus L, Lang S, Gantz S, et al. Spinal Cord Injury Pain Instrument and painDETECT questionnaire: Convergent construct validity in individuals with Spinal Cord Injury. Eur J Pain. 2017;21:1642-56.

8. Bryce TN, Richards JS, Bombardier CH, Dijkers MP, Fann JR, Brooks L, et al. Screening for neuropathic pain after spinal cord injury with the Spinal Cord Injury Pain Instrument (SCIPI): A preliminary validation study. Spinal Cord. 2014;52:407-12.

9. Wong ML, Fleming L, Robayo LE, Widerström-Noga E. Utility of the Neuropathic Pain Symptom Inventory in people with spinal cord injury. Spinal Cord. 2020;58:35-42.

10. Norrbrink C, Lindberg T, Wahman K, Bjerkefors A. Effects of an exercise programme on musculoskeletal and neuropathic pain after spinal cord injury-Results from a seated double-poling ergometer study. Spinal Cord. 2012;50:457-61.

11. Sato G, Osumi M, Morioka S. Effects of wheelchair propulsion on neuropathic pain and resting electroencephalography after spinal cord injury. J Rehabil Med. 2017;49:136-43.

12. Todd KR, Martin Ginis KA. An examination of diurnal variations in neuropathic pain and affect, on exercise and non-exercise days, in adults with spinal cord injury. Spinal Cord Ser Cases. 2018;4. https://doi.org/10.1038/s41394-018-0130-3.

13. Sateia MJ, Buysse DJ, Krystal AD, Neubauer DN, Heald JL. Clinical Practice Guideline for the Pharmacologic Treatment of Chronic Insomnia in Adults: An American academy of sleep medicine clinical practice guideline. J Clin Sleep Med. 2017;13:307-49.

14. Parikh SV, Quilty LC, Ravitz P, Rosenbluth M, Pavlova B, Grigoriadis S, et al. Canadian Network for Mood and Anxiety Treatments (CANMAT) 2016 clinical guidelines for the management of adults with major depressive disorder: Section 2. Psychological treatments. Can J Psychiatry. 2016;61:524-39.

15. Milev RV, Giacobbe P, Kennedy SH, Blumberger DM, Daskalakis ZJ, Downar J, et al. Canadian Network for Mood and Anxiety Treatments (CANMAT) 2016 clinical guidelines for the management of adults with major depressive disorder: Section 4. Neurostimulation treatments. Can J Psychiatry. 2016;61:561-75.

16. Ravindran AV, Balneaves LG, Faulkner G, Ortiz A, Mclntosh D, Morehouse RL, et al. Canadian Network for Mood and Anxiety Treatments (CANMAT) 2016 clinical guidelines for the management of adults with major depressive disorder: Section 5. Complementary and Alternative Medicine Treatments. Can J Psychiatry. 2016;61:576-87.

17. Heutink M, Post MW, Luthart $P$, Schuitemaker M, Slangen S, Sweers J, et al. Longterm outcomes of a multidisciplinary cognitive behavioural programme for coping with chronic neuropathic spinal cord injury pain. J Rehabil Med. 2014;46:540-5

18. Heutink M, Post MW, Bongers-Janssen HM, Dijkstra CA, Snoek GJ, Spijkerman $D C$, et al. The CONECSI trial: results of a randomized controlled trial of a multidisciplinary cognitive behavioral program for coping with chronic neuropathic pain after spinal cord injury. Pain. 2012;153:120-8.

19. Perry KN, Nicholas MK, Middleton JW. Comparison of a pain management program with usual care in a pain management center for people with spinal cord injury-related chronic pain. Clin J Pain. 2010;26:206-16.

20. Norrbrink Budh C, Kowalski J, Lundeberg T. A comprehensive pain management programme comprising educational, cognitive and behavioural interventions for neuropathic pain following spinal cord injury. J Rehabil Med. 2006;38:172-80.

21. Burns AS, Delparte JJ, Ballantyne EC, Boschen KA. Evaluation of an interdisciplinary program for chronic pain after spinal cord injury. PM R. 2013;5:832-8.

22. Siddall PJ, Cousins MJ, Otte A, Griesing T, Chambers R, Murphy TK. Pregabalin in central neuropathic pain associated with spinal cord injury: A placebocontrolled trial. Neurology. 2006;67:1792-1800.
23. Cardenas DD, Nieshoff EC, Suda K, Goto S-I, Sanin L, Kaneko T, et al. A randomized trial of pregabalin in patients with neuropathic pain due to spinal cord injury. Neurology. 2013;80:533-9.

24. Vranken $J H$, Dijkgraaf MGW, Kruis $M R$, van der Vegt $M H$, Hollmann MW, Heesen M. Pregabalin in patients with central neuropathic pain: A randomized, double-blind, placebo-controlled trial of a flexible-dose regimen. Pain. 2008;136:150-7.

25. Cardenas DD, Nieshoff EC, Whalen E, Scavone JM. Cardenas DD - A randomized trial of pregabalin in patients with. Neurology. 2013;2013:533-9.

26. Guzelkucuk U, Duman I, Yilmaz B, Tan AK. Reversible post-pregabalin peripheral edema in a spinal cord injury patient. Spinal Cord. 2012;50:472-3.

27. Kaydok E, Levendoglu F, Ozerbil MO, Karahan AY. Comparison of the efficacy of gabapentin and pregabalin for neuropathic pain in patients with spinal cord injury: a crossover study. Acta Medica Mediterranea. 2014;30:1343-8.

28. Yilmaz B, Yasar E, Koroglu Omac O, Goktepe AS, Tan AK. Gabapentin vs. Pregabalin for the Treatment of Neuropathic Pain in Patients with Spinal Cord Injury: A Crossover Study. Türkiye Fiz Tip ve Rehabil Derg. 2015;61:1-5.

29. Yílmaz B, Kesikburun S, Yaşar E, Tan AK. The effect of repetitive transcranial magnetic stimulation on refractory neuropathic pain in spinal cord injury. J Spinal Cord Med. 2014;37:397-400.

30. Kyunghoon M, Yoongul O, Sang-Hyuk L, Ju Seok R. Symptom-Based Treatment of Neuropathic Pain in Spinal Cord-Injured Patients. Am J Phys Med Rehabil. 2016;95:330-8 9p.

31. Mehta S, Mclntyre A, Dijkers M, Loh E, Teasell RW. Gabapentinoids are effective in decreasing neuropathic pain and other secondary outcomes after spinal cord injury: a meta-analysis. Arch Phys Med Rehabil. 2014;95:2180-6.

32. Rintala DH, Holmes SA, Courtade D, Fiess RN, Tastard LV, Loubser PG. Comparison of the Effectiveness of Amitriptyline and Gabapentin on Chronic Neuropathic Pain in Persons With Spinal Cord Injury. Arch Phys Med Rehabil. 2007;88:1547-60.

33. Tai Q, Kirshblum S, Chen B, Millis S, Johnston M, DeLisa JA. Gabapentin in the treatment of neuropathic pain after spinal cord injury: A prospective, randomized, double-blind, crossover trial. J Spinal Cord Med. 2002;25:100-5.

34. Levendoğlu F, Öğün CÖ, Özerbil Ö, Öğün TC, Uğurlu H. Gabapentin Is a First Line Drug for the Treatment of Neuropathic Pain in Spinal Cord Injury. Spine. 2004;29:743-51.

35. To TP, Lim TC, Hill ST, Cooper N, Frauman AG, Kirsa SW, et al. Gabapentin for neuropathic pain following spinal cord injury. Spinal Cord. 2002;40:282-5.

36. Putzke JD, Richards JS, Kezar L, Hicken BL, Ness TJ. Long-term use of gabapentin for treatment of pain after traumatic spinal cord injury. Clin J Pain. 2002;18:116-21.

37. Ahn SH, Park HW, Lee BS, Moon HW, Jang SH, Sakong J, et al. Gabapentin effect on neuropathic pain compared among patients with spinal cord injury and different durations of symptoms. Spine (Phila Pa 1976). 2003;28:341-7.

38. Mehta S, Guy S, Lam T, Teasell R, Loh E. Antidepressants are effective in decreasing neuropathic pain after SCl: A meta-analysis. Top Spinal Cord Inj Rehabil. 2015;21:166-73.

39. Cardenas DD, Warms CA, Turner JA, Marshall H, Brooke MM, Loeser JD. Efficacy of amitriptyline for relief of pain in spinal cord injury: results of a randomized controlled trial. Pain. 2002:96:365-73.

40. Jefferies K. Treatment of neuropathic pain. Semin Neurol. 2010;30:425-32.

41. Agarwal N, Joshi M. Effectiveness of amitriptyline and lamotrigine in traumatic spinal cord injury-induced neuropathic pain: A randomized longitudinal comparative study. Spinal Cord. 2017;55:126-30.

42. Preuss CV, Randhawa G, Wy TJP, Saadabadi A. Oxcarbazepine. StatPearls Publishing; 2020. http://www.ncbi.nlm.nih.gov/pubmed/29493938. Accessed 12 Feb 2021.

43. Norrbrink C, Lundeberg T. Tramadol in neuropathic pain after spinal cord injury a randomized, double-blind, placebo-controlled trial. Clin J Pain. 2009:25:177-84.

44. Canadian Guideline for Safe and Effective Use of Opioids for Chronic NonCancer Pain. Canada: National Opioid Use Guideline Group (NOUGG), 2010. Available at http://nationalpaincentre.mcmaster.ca/opioid/

45. Park SH, Wackernah RC, Stimmel GL. Serotonin syndrome: Is it a reason to avoid the use of tramadol with antidepressants? J Pharm Pract 2014;27:71-78.

46. Finnerup NB, Sindrup SH, Bach FW, Johannesen IL, Jensen TS. Lamotrigine in spinal cord injury pain: a randomized controlled trial. Pain. 2009;96:375-83.

47. Han Z-A, Song DH, Oh H-M, Chung ME. Botulinum toxin type A for neuropathic pain in patients with spinal cord injury. Ann Neurol. 2016;79:569-78 10p.

48. Fregni F, Gimenes R, Valle AC, Ferreira MJ, Rocha RR, Natalle $L$, et al. A randomized, sham-controlled, proof of principle study of transcranial direct current stimulation for the treatment of pain in fibromyalgia. Arthritis Rheum. 2006:54:3988-98.

49. Ngernyam N, Jensen MP, Arayawichanon P, Auvichayapat N, Tiamkao S, Janjarasjitt $S$, et al. The effects of transcranial direct current stimulation in patients 
with neuropathic pain from spinal cord injury. Clin Neurophysiol. 2015;126:382-90.

50. Soler MD, Kumru H, Pelayo R, Vidal J, Tormos JM, Fregni F, et al. Effectiveness of transcranial direct current stimulation and visual illusion on neuropathic pain in spinal cord injury. Brain. 2010;133:2565-77.

51. Wrigley PJ, Gustin SM, McIndoe LN, Chakiath RJ, Henderson LA, Siddall PJ. Longstanding neuropathic pain after spinal cord injury is refractory to transcranial direct current stimulation: a randomized controlled trial. Pain. 2013;154:2178-84.

52. Yoon EJ, Kim YK, Kim HR, Kim SE, Lee Y, Shin HI. Transcranial direct current stimulation to lessen neuropathic pain after spinal cord injury: a mechanistic PET study. Neurorehabil Neural Repair. 2014;28:250-9.

53. Mehta S, Mcintyre A, Guy S, Teasell RW, Loh E. Effectiveness of transcranial direct current stimulation for the management of neuropathic pain after spinal cord injury: a meta-analysis. Spinal Cord. 2015;53:780-5.

54. Thibaut A, Carvalho S, Morse LR, Zafonte R, Fregni F. Delayed pain decrease following $M 1$ tDCS in spinal cord injury: a randomized controlled clinical trial. Neurosci Lett. 2017;658:19-26.

55. Srivastav AK, Sharma N, Khadayat S. Commentary on: 'Combined transcranial direct current stimulation and breathing-controlled electrical stimulation for the management of neuropathic pain after spinal cord injury'. J Rehabil Med 2019;51:622-3

56. Jensen MP, Sherlin LH, Askew RL, Fregni F, Witkop G, Gianas A, et al. Effects of non-pharmacological pain treatments on brain states. Clin Neurophysiol. 2013;124:2016-24.

57. Auvichayapat $\mathrm{P}$, Keeratitanont $\mathrm{K}$, Janyachareon $\mathrm{T}$, Auvichayapat N. The effects of transcranial direct current stimulation on metabolite changes at the anterior cingulate cortex in neuropathic pain: a pilot study. J Pain Res. 2019;11:2301-9.

58. Kumru H, Soler D, Vidal J, Navarro X, Tormos JM, Pascual-Leone A, et al. The effects of transcranial direct current stimulation with visual illusion in neuropathic pain due to spinal cord injury: an evoked potentials and quantitative thermal testing study. Eur J Pain. 2013;17:55-66.

59. Wilsey B, Marcotte TD, Deutsch R, Zhao H, Prasad H, Phan A. An Exploratory Human Laboratory Experiment Evaluating Vaporized Cannabis in the Treatment of Neuropathic Pain From Spinal Cord Injury and Disease. J Pain. 2016;17:982-1000.

60. Rintala DH, Fiess RN, Tan G, Holmes SA, Bruel BM. Effect of dronabinol on central neuropathic pain after spinal cord injury: A pilot study. Am J Phys Med Rehabil. 2010;89:840-8.

61. Cichocki $M$, Sönnichsen A. Transcutaneous electrical nerve stimulation for treatment of neuropathic pain. Z Allgemeinmed 2019;2019:435-7.

62. Davis R, Lentini R. Transcutaneous nerve stimulation for treatment of pain in patients with spinal cord injury. Surg Neurol. 1975;4:100-1.

63. Celik EC, Erhan B, Gunduz B, Lakse E. The effect of low-frequency TENS in the treatment of neuropathic pain in patients with spinal cord injury. Spinal Cord. 2013;51:334-7.

64. Özkul Ç, Kilinç M, Yildirim SA, Topçuołlu EY, Akyüz M. Effects of visual illusion and transcutaneous electrical nerve stimulation on neuropathic pain in patients with spinal cord injury: a randomised controlled cross-over trial. J Back Musculoskelet Rehabil. 2015;28:709-19.

65. Zeb A, Arsh A, Bahadur S, llyas SM. Effectiveness of transcutaneous electrical nerve stimulation in management of neuropathic pain in patients with post traumatic incomplete spinal cord injuries. Pak J Med Sci. 2018;34:1177-80.

66. Barrera-Chacon JM, Mendez-Suarez JL, Jauregui-Abrisqueta ML, Palazon R, Barbara-Bataller E, Garcia-Obrero I. Oxycodone improves pain control and quality of life in anticonvulsant-pretreated spinal cord-injured patients with neuropathic pain. Spinal Cord. 2011;49:36-42.

67. Dworkin $\mathrm{RH}, \mathrm{O}^{\prime}$ Connor $\mathrm{AB}$, Backonja $\mathrm{M}$, Farrar JT, Finnerup NB, Jensen $\mathrm{TS}$, et al. Pharmacologic management of neuropathic pain: Evidence-based recommendations. Pain. 2007;132:237-51.

68. Falci S, Best L, Bayles R, Lammertse D, Starnes C. Dorsal root entry zone microcoagulation for spinal cord injury-related central pain: operative intramedullary electrophysiological guidance and clinical outcome. J Neurosurg. 2002;97:193-200.

69. Chun HJ, Kim YS, Yi HJ. A modified microsurgical DREZotomy procedure for refractory neuropathic pain. World Neurosurg. 2011;75:551-7.

70. Spaić M, Marković N, Tadić R. Microsurgical DREZotomy for pain of spinal cord and cauda equina injury origin: clinical characteristics of pain and implications for surgery in a series of 26 patients. Acta Neurochir (Wien). 2002;144:453-62.

71. Sindou M, Mertens $P$, Wael M. Microsurgical DREZotomy for pain due to spinal cord and/or cauda equina injuries: Long-term results in a series of 44 patients. Pain. 2001;92:159-71.

72. Chivukula S, Tempel ZJ, Chen CJ, Shin SS, Gande AV, Moossy JJ. Spinal and Nucleus Caudalis Dorsal Root Entry Zone Lesioning for Chronic Pain: Efficacy and Outcomes. World Neurosurg. 2015;84:494-504.
73. Tao W, Hu YS, Chen F, Zhang XH, Li YJ. Microsurgical dorsal root entry zone coagulation for chronic neuropathic pain due to spinal cord and/or cauda equina injuries. Chin Med J. 2014;127:182-4.

74. Falci S, Indeck C, Barnkow D. Spinal cord injury below-level neuropathic pain relief with dorsal root entry zone microcoagulation performed caudal to level of complete spinal cord transection. J Neurosurg Spine. 2018;28:612-20.

75. Finnerup NB, Grydehoj J, Bing J, Johannesen IL, Biering-Sorensen F, Sindrup SH, et al. Levetiracetam in spinal cord injury pain: a randomized controlled trial. Spinal Cord. 2009;47:861-7.

76. Chiou-Tan FY, Tuel SM, Johnson JC, Priebe MM, Hirsh DD, Strayer JR. Effect of mexiletine on spinal cord injury dysesthetic pain. Am J Phys Med Rehabil. 1996;75:84-87.

77. Gui Y, Li H, Zhao M, Yang Q, Kuang X. Effect of intermittent normobaric hyperoxia for treatment of neuropathic pain in Chinese patients with spinal cord injury. Spinal Cord. 2015;53:238-42.

78. Hassan MA, Fraser M, Conway BA, Allan DB, Vuckovic A. The mechanism of neurofeedback training for treatment of central neuropathic pain in paraplegia: a pilot study. BMC Neurol. 2015;15:200.

79. Jensen MP, Gertz KJ, Kupper AE, Braden AL, Howe JD, Hakimian S, et al. Steps toward developing an EEG biofeedback treatment for chronic pain. Appl Psychophysiol Biofeedback. 2013;38:101-8.

80. Allison DJ, Thomas A, Beaudry K, Ditor DS. Targeting inflammation as a treatment modality for neuropathic pain in spinal cord injury: a randomized clinical trial. J Neuroinflammation. 2016;13:152.

81. Andresen SR, Bing J, Hansen RM, Biering-Sorensen F, Johannesen IL, Hagen EM, et al. Ultramicronized palmitoylethanolamide in spinal cord injury neuropathic pain: a randomized, double-blind, placebo-controlled trial. Pain. 2016;157:2097-103.

82. Li S, Davis M, Frontera JE, Li S. A novel nonpharmacological intervention -breathing-controlled electrical stimulation for neuropathic pain management after spinal cord injury-A preliminary study. J Pain Res. 2016;9:933-40.

83. Karri J, Li S, Zhang L, Chen YT, Stampas A, Li S. Neuropathic pain modulation after spinal cord injury by breathing-controlled electrical stimulation (BreEStim) is associated with restoration of autonomic dysfunction. J Pain Res. 2018;11:2331-41.

84. Sang CN, Barnabe KJ, Kern SE. Phase IA Clinical Trial Evaluating the Tolerability, Pharmacokinetics, and Analgesic Efficacy of an Intrathecally Administered Neurotensin A Analogue in Central Neuropathic Pain Following Spinal Cord Injury. Clin Pharm Drug Dev. 2016;5:250-8.

85. Vaquero J, Zurita M, Rico MA, Aguayo C, Bonilla C, Marin E, et al. Intrathecal administration of autologous mesenchymal stromal cells for spinal cord injury: Safety and efficacy of the 100/3 guideline. Cytotherapy. 2018;20:806-19.

86. Vaquero J, Zurita M, Rico MA, Bonilla C, Aguayo C, Fernández C, et al. Repeated subarachnoid administrations of autologous mesenchymal stromal cells supported in autologous plasma improve quality of life in patients suffering incomplete spinal cord injury. Cytotherapy. 2017;19:349-59.

87. Vaquero J, Zurita M, Rico MA, Aguayo C, Fernández C, Gutiérrez R, et al. Intrathecal administration of autologous bone marrow stromal cells improves neuropathic pain in patients with spinal cord injury. Neurosci Lett. 2018;670:14-18.

88. Mendonça MVP, Larocca TF, Souza BSDF, Villarreal CF, Silva LFM, Matos AC, et al. Safety and neurological assessments after autologous transplantation of bone marrow mesenchymal stem cells in subjects with chronic spinal cord injury. Stem Cell Res Ther. 2014;5. https://doi.org/10.1186/scrt516.

89. Chen FC, Shao HL, Han FL. A pilot study of neuromuscular electrical stimulation for neuropathic pain caused by spinal cord injury. Medicine. 2018;97:11658.

90. Kumru H, Albu S, Kofler M, Vidal J. The long-term analgesic effect of intrathecal baclofen on neuropathic pain in patients with spinal cord injury. Neurologia 2020;35:679-81.

91. Vitalii $C$, Oleg $P$. The efficiency of transcutaneous electrical nerve stimulation in association with gabapentin in the treatment of neuropathic pain in patients with spinal cord injury. Rom J Neurol Rev Rom Neurol. 2014;13:193-6.

92. Kressler J, Thomas CK, Field-Fote EC, Sanchez J, Widerstrom-Noga E, Cilien DC, et al. Understanding therapeutic benefits of overground bionic ambulation: exploratory case series in persons with chronic, complete spinal cord injury. Arch Phys Med Rehabil. 2014;95:1878-87 1874.

93. Richards JS, Bombardier CH, Wilson CS, Chiodo AE, Brooks L, Tate DG, et al. Efficacy of venlafaxine XR for the treatment of pain in patients with spinal cord injury and major depression: a randomized, controlled trial. Arch Phys Med Rehabil. 2015;96:680-9.

94. Jensen MP, Barber J. Hypnotic analgesia of spinal cord injury pain. Aust J Clin Exp Hypn. 2000;28:150-68.

95. Defrin R, Grunhaus L, Zamir D, Zeilig G. The effect of a series of repetitive transcranial magnetic stimulations of the motor cortex on central pain after spinal cord injury. Arch Phys Med Rehabil. 2007;88:1574-80. 
96. Kang BS, Shin HI, Bang MS. Effect of repetitive transcranial magnetic stimulation over the hand motor cortical area on central pain after spinal cord injury. Arch Phys Med Rehabil. 2013;90:1766-71.

97. Jette F, Cote I, Meziane HB, Mercier C. Effect of single-session repetitive transcranial magnetic stimulation applied over the hand versus leg motor area on pain after spinal cord injury. Neurorehabil Neural Repair. 2013;27:636-43.

98. Nardone R, Höller Y, Langthaler PB, Lochner P, Golaszewski S, Schwenker K, et al. RTMS of the prefrontal cortex has analgesic effects on neuropathic pain in subjects with spinal cord injury. Spinal Cord. 2017;55:20-25.

99. Nayak S, Shiflett SC, Schoenberger NE, Agostinelli S, Kirshblum S, Averill A, et al. Is acupuncture effective in treating chronic pain after spinal cord injury? Arch Phys Med Rehabil. 2001;82:1578-86.

100. Norrbrink $C$, Lundeberg T. Acupuncture and massage therapy for neuropathic pain following spinal cord injury: an exploratory study. Acupunct Med. 2011;29:108-15.

101. Rapson LM, Wells N, Pepper J, Majid N, Boon H. Acupuncture as a promising treatment for below-level central neuropathic pain: a retrospective study. J Spinal Cord Med. 2003;26:21-26.

102. Estores I, Chen K, Jackson B, Lao L, Gorman PH. Auricular acupuncture for spinal cord injury related neuropathic pain: a pilot controlled clinical trial. J Spinal Cord Med. 2017;40:432-8.

103. Kopsky DJ, Ettema FW, Leeden M, Dekker J, Stolwijk-Swuste JM. Percutaneous nerve stimulation in chronic neuropathic pain patients due to spinal cord injury: a pilot study. Pain Pr. 2014;14:252-9.

104. Nayak S, Shiflett SC, Schoenberger NE, Agostinelli S, Kirshblum S, Averill A, et al. Is acupuncture effective in treating chronic pain after spinal cord injury? Arch Phys Med Rehabil. 2001;82:1578-86.

105. Moseley GL. Using visual illusion to reduce at-level neuropathic pain in paraplegia. Pain. 2007;130:294-8.

106. Gustin SM, Wrigley PJ, Gandevia SC, Middleton JW, Henderson LA, Siddall PJ. Movement imagery increases pain in people with neuropathic pain following complete thoracic spinal cord injury. Pain. 2008;137:237-44.

107. Jordan M, Richardson EJ. Effects of Virtual Walking Treatment on Spinal Cord InjuryRelated Neuropathic Pain: Pilot Results and Trends Related to Location of Pain and at-level Neuronal Hypersensitivity. Am J Phys Med Rehabil. 2016;95:390-6.

108. Pozeg $P$, Palluel $E$, Ronchi $R$, Solcà $M$, Al-Khodairy AW, Jordan $X$, et al. Virtual reality improves embodiment and neuropathic pain caused by spinal cord injury. Neurology. 2017;89:1894-903.

109. Villiger M, Bohli D, Kiper D, Pyk P, Spillmann J, Meilick B, et al. Virtual realityaugmented neurorehabilitation improves motor function and reduces neuropathic pain in patients with incomplete spinal cord injury. Neurorehabil Neural Repair. 2013;27:675-83.

110. Kvarnström A, Karlsten R, Quiding $H$, Gordh $T$. The analgesic effect of intravenous ketamine and lidocaine on pain after spinal cord injury. Acta Anaesthesiol Scand. 2004;48:498-506.

111. Eide PK, Stubhaug A, Stenehjem AE. Central dysesthesia pain after traumatic spinal cord injury is dependent on N-methyl-D-aspartate receptor activation. Neurosurgery. 1995;37:1080-7.

112. Rabi J, Minori J, Abad H, Lee R, Gittler M. Topical Ketamine 10\% for Neuropathic Pain in Spinal Cord Injury Patients: An Open-Label Trial. Int J Pharm Compd. 2016;20:517-20.

113. Ginis KAM, Latimer AE, McKechnie K, Ditor DS, McCartney N, Hicks AL, et al. Using exercise to enhance subjective well-being among people with spinal cord injury: the mediating influences of stress and pain. Rehabil Psychol. 2003;48:157-64.

114. Cioni B, Meglio M, Pentimalli L, Visocchi M. Spinal cord stimulation in the treatment of paraplegic pain. J Neurosurg. 1995;82:35-39.

115. Arienti C, Daccò S, Piccolo I, Redaelli T. Osteopathic manipulative treatment is effective on pain control associated to spinal cord injury. Spinal Cord. 2011;49:515-9.

116. Vranken JH, Hollmann MW, Van Der Vegt MH, Kruis MR, Heesen M, Vos $K$, et al. Duloxetine in patients with central neuropathic pain caused by spinal cord injury or stroke: a randomized, double-blind, placebo-controlled trial. Pain. 2011;152:267-73.

117. Lunn MPT, Hughes RAC, Wiffen PJ. Duloxetine for treating painful neuropathy, chronic pain or fibromyalgia. Cochrane Database Syst Rev 2014;CD007115. https://doi.org/10.1002/14651858.CD007115

118. Bril V, Perkins B, Toth C. Neuropathy. Can J Diabetes. 2013;37:S142-S144.

119. Attal N, Gaudé V, Brasseur L, Dupuy M, Guirimand F, Parker F, et al. Intravenous lidocaine in central pain: a double-blind, placebo-controlled, psychophysical study. Neurology. 2000;54:564-74

120. Finnerup NB, Biering-Sorensen F, Johannesen IL, Terkelsen AJ, Juhl Gl, Kristensen $A D$, et al. Intravenous lidocaine relieves spinal cord injury pain: a randomized controlled trial. Anesthesiology. 2005;102:1023-30.
121. Siddall PJ, Molloy AR, Walker S, Mather LE, Rutkowski SB, Cousins MJ. The efficacy of intrathecal morphine and clonidine in the treatment of pain after spinal cord injury. Anesth Analg. 2000;91:1493-8.

122. Attal N, Guirimand F, Brasseur L, Gaude V, Chauvin M, Bouhassira D. Effects of IV morphine in central pain: a randomized placebo-controlled study. Neurology. 2002;58:554-63.

\section{ACKNOWLEDGEMENTS}

We thank Andréane Richard-Denis, Brenda Lau, Neal McKinnon, James Milligan, and Keith Sequeira for providing critical review and feedback as external reviewers.

\section{AUTHOR CONTRIBUTIONS}

EL acted as chair. ARA, BB, SM, MM, and DJA acted as members of the steering committee. TNB, SG, TJ, AK-D, DK, OL, GL-T-F, DEM, CO'C, SO, PP, JWM, CS, RT, AT, EW$\mathrm{N}, \mathrm{DLW}$, and NX acted as members of the expert panel. All authors contributed to critical review of the literature, content development within the guidelines, and review/editing of the manuscript.

\section{FUNDING}

Funding for the research and publication of this supplement is provided by the Ontario Neurotrauma Foundation in their mission to advance the care of people with spinal cord injury (Grant 2018-RHI-GUIDE-1049).

\section{COMPETING INTERESTS}

TJ is employed by the Ontario Neurotrauma Foundation. DEM reports personal fees from Canopy Growth Inc, outside the submitted work. $\mathrm{CO}^{\prime} \mathrm{C}$ reports grants from Praxis Spinal Cord Institute, other from Cytokinetics, other from Orion, other from Mallinckrodt, grants from New Brunswick Health Research Foundation, personal fees from Spectrum/Canopy, personal fees from Shoppers Drug Mart, grants and personal fees from IPSEN, personal fees from MT Pharma, personal fees from Tilray, personal fees from Allergan, personal fees from Roche, outside the submitted work. RT reports other funding from Allergan (Predictive Model for Treatment of Spasiticity Post Stroke (Botox), chair positions on data monitoring/advisory boards for studies on statins for osteoporosis after $\mathrm{SCl}$ and exercise in $\mathrm{SCl}$, and medicolegal work for assessment of individuals with whiplash and other musculoskeletal injuries after motor vehicle accidents outside the submitted work. All other authors have nothing to disclose.

\section{ADDITIONAL INFORMATION}

Supplementary information The online version contains supplementary material available at https://doi.org/10.1038/s41393-021-00744-z.

Correspondence and requests for materials should be addressed to Eldon Loh.

Reprints and permission information is available at http://www.nature.com/reprints

Publisher's note Springer Nature remains neutral with regard to jurisdictional claims in published maps and institutional affiliations.

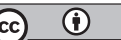

Open Access This article is licensed under a Creative Commons Attribution 4.0 International License, which permits use, sharing, adaptation, distribution and reproduction in any medium or format, as long as you give appropriate credit to the original author(s) and the source, provide a link to the Creative Commons license, and indicate if changes were made. The images or other third party material in this article are included in the article's Creative Commons license, unless indicated otherwise in a credit line to the material. If material is not included in the article's Creative Commons license and your intended use is not permitted by statutory regulation or exceeds the permitted use, you will need to obtain permission directly from the copyright holder. To view a copy of this license, visit http://creativecommons. org/licenses/by/4.0/.

(c) The Author(s) 2022 